\title{
Del romanticismo erudito al juicio científico: balance bibliográfico de los estudios sobre Fernando de Córdoba
}

\section{From erudite romanticism to scientific judgment: bibliographical balance of the scholarship on Fernando de Córdoba}

\author{
Miguel SARALEgUi \\ Universidad Diego Portales (Chile)
}

Recibido: 20/01/2014

Aceptado: 14/11/2014

\section{Resumen}

Fernando de Córdoba es uno de los grandes pensadores españoles del siglo XV. Lamentablemente su figura no ha alcanzado la atención debida entre los estudiosos dedicados al pensamiento español, lo que ha hecho que tan sólo se disponga de una edición moderna de uno de sus escritos y ninguna traducción al castellano. Los méritos de su pensamiento -ya sólo la participación en la polémica entre Platón y Aristóteles a favor del primero con su Laudibus Platonis- exigen que este vacío de bibliografía primaria sea remediado. Como paso preliminar, se presenta este artículo en el que se repasan todas las aportaciones que, a lo largo de ya casi ciento cincuenta años, se han hecho sobre este autor. A pesar de su más bien escasa influencia, este examen bibliográfico muestra cómo la misma obra de Fernando de Córdoba ha sido interpretada de acuerdo a criterios externos y a debates más amplios, en los que la postura de Córdoba aparecía prejuzgada sin tener en cuenta lo transmitido en sus textos. Precisamente, el objetivo de este artículo como propedéutica para un estudio más pormenorizado de sus obras -especialmente de De iure medios exigendi fructus quos vulgo annatos dicunt et romani pontificis in temporalibus potestate- consistirá en diferenciar las aportaciones sólidas de aquellas que utilizan a Córdoba de modo interesado.

Palabras clave: Fernando de Córdoba, bibliografía, filosofía española. 


\begin{abstract}
Fernando de Córdoba is one of the greatest Spanish philosophers of the $\mathrm{XV}^{\text {th }}$ century. Because of the academical neglection of this philosopher, only exists one modern edition of his works and no translation to Spanish of his books originally written in Latin. The signification of his thought - he was the first to participate in the Aristotle-Plato controversy, being the first to deffend Plato in Laudibus Platonis-demands to fill this absense of studies. As a preliminary step, this article studies the trend of bibliographical scholarship since it was born one hundred and fifty years ago. Most of these studies offer a prejudicial view of Cordoba, normally including him in more polemical debates, such as the one of the existence of Spanish Philosophy. The object of this article is to offer a guide to those who want to pursue in the study of Fernando de Córdoba, informing about which works could serve for the more elaborate research and which should be discarded.
\end{abstract}

Keywords: Fernando de Córdoba, bibliography, spanish philosophy.

Fernando de Córdoba sigue siendo una figura relativamente desconocida para los historiadores de la filosofía española y, en general, para la historia de la filosofía del siglo XV1. A pesar de que la despreocupación no ha sido absoluta ${ }^{2}$, a Córdoba le aqueja el mismo mal que a tantos otros pensadores españoles del incipiente Humanismo. El lamento del editor de una suerte de Vidas ilustres promovida por la Real Academia a fines del XVIII todavía se puede reproducir hoy: «Las pocas noticias circunstanciadas, y aun la ninguna idea que se tiene de muchos de los españoles ilustres que florecieron antes del reinado de Isabel y Fernando, son consecuencias necesarias de aquel principio [...], de muchos se ha perdido el nombre; o si se conserva es con una oscuridad que hace dudosa o inútil su existencia» ${ }^{3}$.

\footnotetext{
${ }^{1}$ Este trabajo se enmarca en el proyecto HAR 2013-45788-C4-3-P. Es necesario señalar que, en ninguna de las antologías sobre filosofía española del Renacimiento, se ha incluido un texto de Fernando de Córdoba. La ausencia ya se puede notar en la Biblioteca de Autores Españoles de Rivadeneira, cuyo tomo 65, Obras escogidas de filósofos, está compuesta por textos de Séneca, Lulio, Alonso Tostado, Antonio de Guevara, Bartolomé de las Casas, Bartolomé de Albornoz, Vives, Simón Abril, Melchor Cano, Oliva Sabuco, Pérez de la Oliva, Huarte de San Juan, Joaquín Setanti y Gracián». Más recientemente, A. Martínez de Arancón (ed.), Antología de humanistas españoles, Editora Nacional, Madrid, 1980 tampoco incluye ningún texto. También historias de la filosofía española ignoran a este autor, como por ejemplo F. Urales, La evolución de la filosofía en España, Revista Blanca, Barcelona, 1934, vols. II.

2 Un filósofo de este periodo sobre el que el desinterés ha sido aún mayor es Pedro García y su obra Determinationes magistrales contra conclusiones apologales Joannis Pici Mirandulani, Eucario Silver, Roma, 1499.

3 Anónimo, Retrato de los españoles ilustres con una epitome de sus vidas, Imprenta Real, Madrid, 1791, s. p. (Prólogo).
} 
Córdoba no ha pasado al mainstream de la historiografía de la filosofía del Renacimiento. Su De laudibus Platonis, que inaugura la defensa de Platón tras los ataques de Trebisonda en las Comparationes Philosophorum Platonis et Aristotelis, no le ha valido más que una sola línea de gloria en algunas historias generales de la filosofía o de la teología 4 . De este modo que uno de los más importantes historiadores de la filosofía española, Adolfo Bonilla, y del Renacimiento, John Monfasani, le hayan prestado atención no ha conseguido que Córdoba saliera del olvido y del desconocimiento en que todavía hoy se encuentra encerrado.

Considero que la falta de interés por este pensador se debe principalmente a que todavía una gran parte de sus obras -sobre todo De laudibus platonis así como un interesante corpus sobre fillosofía política y eclesiología- no se ha editado. También contribuye a este desconocimiento que ninguno de su escritos haya sido traducido al castellano. Nuevamente esta situación editorial es compartida por muchos otros pensadores del siglo XV español5. Sólo a través de la edición y traducción de su corpus, esta figura podrá ocupar el lugar que le corresponde, secundario, pero no marginal, para la historia de la filosofía del siglo XV y absolutamente nuclear para la historia de la filosofía española, no sólo de este periodo. Considero que, como propedéutica, de esta labor crítica, a la cual deberá seguir el análisis de su polifacético pensamiento -que se extiende desde la metafísica y la lógica a la eclesiología, la teoría política y la ciencia médica-, es necesario realizar un estudio bibliográfico sobre las opiniones que de este autor se han ofrecido desde que en 1882 Julien Havet publicara su pionero artículo. Este trabajo ha de resultar útil para que los futuros trabajos -filológicos e histórico-filosóficos- se asienten sobre pilares sólidos.

\section{II}

La figura de Fernando de Córdoba nunca dejó de ejercer un cierto peso entre los pensadores y escritores interesados por la cultura española. De este modo, figuras

\footnotetext{
${ }^{4}$ R. García Villoslada y B. Llorca, Historia de la Iglesia Católica. III Edad Nueva, Biblioteca de autores cristianos, Madrid, 2010 [1960], p. 649: «Pasmo de los escolásticos de París y de Colonia tanto como de los humanistas de Italia, Fernando de Córdoba poseía una memoria portentosa; escribió varios tratados fillosóficos, uno de ellos, De laudibus Platonis, por consejo del general Bessarión».

5 Entre estos, se puede encontrar Ródrigo Sánchez de Arévalo, aunque el Speculum vitae humanae fue traducido al castellano en el mismo siglo XV (Paulo Vrus de Constancia, Zaragoza, 1498). Para la situación de las ediciones de Sánchez de Arévalo, cfr. J. L. Fuertes Herreros, "Filosofía de la historia y utopía en el XV. Una aproximación al Speculum vitae humanae (1468) de Ródrigo Sánchez de Arévalo" en J. M. Soto Rábanos (ed.), Pensamiento medieval hispano. Homenaje a Horacio SantiagoOtero, CSIC, Madrid, 1998, pp. 1317-1320. El estudio del pensamiento de Rodrigo Sánchez de Arévalo no se encuentra tan desatendido, pues existen varias traducciones modernas al castellano. Se puede mencionar, entre las recientes, Deberes y funciones de generales, capitanes y gobernadores, Introducción, edición crítica y traducción de Antonio López Fonseca y José Manuel Ruiz Vila, Madrid, Escolar y Mayo Editores, 2011 y Espejo de la vida humana, Introducción, edición crítica y traducción de José Manuel Ruiz Vila, Madrid, Escolar y Mayo Editores, 2012.
} 
de la talla de Pedro Sánchez Ciruelo en el siglo XVI ${ }^{6}$ y Benito Jerónimo Feijóo en el siglo XVIII hablaron de Fernando de Córdoba. No resulta, sin embargo, problemático considerar que los estudios modernos sobre Fernando de Córdoba comienzan con el artículo de Julien Havet de 1882: "Maître Fernand de Cordove et l'université de Paris au XVe siècle"7.

Julien Havet (1853-1893) fue un historiador francés, formado en la Escuela Nacional des Chartes y en la Escuela de Altos Estudios. Su campo de especialización fue la historia merovingia y carolingia. A pesar del acuerdo en considerar a Havet un pionero, él mismo considera que la figura de Fernando de Córdoba no era del todo desconocida antes de él ${ }^{8}$. El historiador francés se sentirá principalmente interesado por la biografía del filósofo español. Fernando de Córdoba habría participado en acontecimientos de importancia para «la historia de la villa y de la universidad de París» 9 . Aunque Havet señala que Fernando pasó por Italia antes de llegar a París y describe con cierto detalle la relación que mantuvo con Besarión, la figura descrita en este artículo resulta esencialmente parisina. Cita y traduce la biografía que lleva a cabo Tritemio (Johannes von Trittenheim), cuya credibilidad, sin embargo, pone en duda 10 .

La personalidad de Fernando se caracteriza en el episodio parisino por dos notas, en cierta medida contrastantes. Por un lado, aparece dotado de numerosas habilidades y destrezas. Ha realizado estudios de derecho, civil y canónico, teología $\mathrm{y}$ artes liberales. Se sabe a numerosos autores de memoria, lo que no puede extrañar ya que le basta leer una página para retener su contenido. También destaca por su capacidad lingüística, pues conoce el latín, el hebreo, el griego, el caldeo y el árabe. Harían falta cien años para aprender lo que él sabe. Por otro lado, gran parte del auditorio parisino no podía creer que Fernando hubiese obtenido esas habilidades de modo natural. Por eso, algunos habrían considerado que sus talentos eran un regalo del demonio, mientras que otros, más exaltadamente, lo habrían identificado con el Anticristo. Havet explica que el ambiente era propicio a este tipo de consideraciones, pues circulaban escritos, como los de Juan de París o de San Vicente Ferrer, que anunciaban la venida del Anticristo antes de que el siglo XV terminara ${ }^{11}$.

\footnotetext{
6 P. Sánchez Ciruelo Paradoxae quaestiones decem, 1538, en M. Andrés, La teología española en el siglo XVI, BAC, Madrid, 1976, vol. I, p. 295, habla positivamente de Fernando de Córdoba, quien hizo una «permixtio artis dialecticae Aristotelis cum arte Raimundo Lulii».

7 Publicado originalmente en Mémoires de la Société de l'histoire de Paris et de l'Ille-de-France, 1882, IX. Se cita a partir de una edición posterior: J. Havet, Oeuvres. Tome II: Opuscules Divers, Ernest Leroux, París, 1896, pp. 310-338.

8 Ibidem, p. 311.

9 Ibidem, p. 310.

10 Ibidem, p. 327: «Mais Trithème a ajouté ce renseignement à ceux qu'il avait tirés de la lettre au chancelier de Brabant; or, en général, comme l'a fait remarquer M. Gaston Paris, «tout ce que Trithème ajoute aux sources qu'il a eues sous les yeux est de pure invention». Il peut bien en être ainsi dans ce cas»».
}

11 Ibidem, p. 326. 
A pesar de describir las tiranteces de la relación con Besarión ${ }^{12}$, la aproximación de Havet a Córdoba resulta sumamente positiva. Centrada en lo biográfico y con apenas apuntes a su filosofía -se ofrece un índice de obras al final del artículolo considera una figura admirable13. Por este motivo, no deja de reprender a los académicos parisinos contemporáneos de Córdoba, quienes, envidiosos, no habrían tratado a Córdoba como debían: «superado este mal trago, sin ninguna duda Fernando de Córdoba se apresuró a abandonar una villa en la que los sabios extranjeros recibían una acogida tan poco alentadora» 14 .

De los tres autores franceses que se dedicaron a Fernando de Córdoba, es Alfred Morel Fatio (1850-1927) el único que se interesó profesionalmente por la cultura española, de la que fue uno de los más importantes especialistas de su tiempo. Formado en la escuela nacional de Chartes, escribió obras sobre diferentes capítulos de nuestra historia literaria, redactando un catálogo de los manuscritos españoles y portugueses conservados en la Biblioteca Nacional de París 15 . No sólo fue miembro de la Real Academia de la Lengua, sino que mantuvo contacto con los principales estudiosos españoles, siendo su correspondencia con Marcelino Menéndez Pelayo el testimonio más importante16.

El artículo de A. Morel Fatio sobre Fernando de Córdoba -"Maître Fernand de Cordove et les humanistes italiens du XVe siècle", que está incluido en una obra dedicada a la memoria del recién desaparecido Havet 17 , es trece años posterior al escrito apenas comentado. En su trabajo, Morel Fatio se limita a extender la biografía de Fernando de Córdoba, dándole un color más internacional y, sobre todo, italiano.

Tras exaltar la figura de Havet y considerarlo un verdadero rescatador de Córdoba ${ }^{18}$, Morel Fatio describe un episodio anterior y posterior al capítulo parisiense. El primero de ellos describe la estancia napolitana de Córdoba, basándose en la carta en la que Valla lo menciona. Encontramos en la descripción del humanista romano -al menos en su parte positiva-características similares a las crónicas

12 Ibidem, p. 328: «Cette brusque décision paralt avoir blessé un peu Fernand de Cordoue; dans la dédicace du nouvel ouvrage, qu'il lui adressa quelque temps après, tout en donnant à son bienfaiteur des marques de son respect et de sa reconnaissance, il ne put s'empêcher de laisser percer aussi un peu d'humeur ou tout au moins de regret».

13 Ibidem, p. 324: «Les textes qui ont été cités aux deux chapitres précédents font assez connaître l'admiration qu'il excita à Paris, ses talents si divers, sa science merveilleuse, sa courtoisie, sa bonne mine».

14 Ibidem, p. 325.

15 A. Morel Fatio, Catalogue des manuscrits espagnols et portugais, Imprimerie National, París, 1892.

16 M. Menéndez Pelayo y A. Morel Fatio, Epistolario, CSIC, Santander, 1953.

17 Publicado en Mélanges Julien Havet, E. Leroux, París, 1895, pp. 521-533.

18 Ibidem, p. 521: «Le mémoire que Julien Havet a consacré à ce curieux Espagnol du XVe siècle compte parmi les meilleurs que soient sortis de la plume de notre ami [...] sortir de ses limbes la figure effacée et obscurcie». 
parisinas. Se alaban los numerosos conocimientos científicos y lingüísticos. Se insiste también en el tópico de que los conocimientos de Córdoba son impropios de un joven. Para alcanzar una sabiduría tan perfecta, Fernando debería haber vivido las tres vidas de Néstor ${ }^{19}$. La segunda prolongación que Morel Fatio lleva a cabo de la biografía de Córdoba consiste en describir el regreso a Italia del joven filósofo. El estudioso sitúa al español en la ciudad ligur en junio de 1446, donde, de nuevo, obtendría un gran éxito como orador. Sin embargo, Morel Fatio señala cómo entre la disputa de Génova y la presencia junto a Besarión en la década de los sesenta, se sigue sin tener ninguna información 20 .

Al igual que la de Havet, la aproximación de Morel Fatio resulta eminentemente positiva. Por este motivo, considera que se puede responsabilizar al «inconmensurable orgullo de los humanistas italianos» de las críticas recibidas en Génova ${ }^{21}$. Sin embargo, en esta presentación, se introducen ya detalles que confieren a la personalidad intelectual de Córdoba un matiz, si no negativo, decididamente ambivalente. De este modo, se insiste en la ambición de Fernando de Córdoba, quien para impactar al auditorio habría exagerado su juventud, lo que provocará diversos problemas y equívocos bibliográficos 22 . Más importante, pues será una nota constante del juicio de la bibliografía española sobre Fernando de Córdoba, se considera a este filósofo un sueño incumplido, una joven promesa que no satisface las expectativas que sus capacidades habían permitido augurar: «Fernando fue, por tanto, una naturaleza excepcionalmente bien dotada y de una precocidad desconocida incluso en los países meridionales, pero, como tantos otros, no pudo cumplir las promesas de la juventud: ni los elogios de Valla, ni los consejos que el humanista le dirigirá indirectamente en su carta a Alfonso hicieron de este prodigio un gran pensador o un gran sabio. Algun tratado de teología y de filosofía que, aunque han sido poco estudiados hasta el momento, no superan, lo que podemos decir claramente, la media de la mayoría de los numerosos escritos análogos de la época: hasta aquí llega todo el bagaje de Fernando de Córdoba cuyos conocimientos y arte de argumentos dejaron estupefactos a los simples, quienes pensaron que tenían algo de sobrenatural, y consiguieron, lo que resulta notable, interesar y atrás el espíritu poderoso de Valla. ¡Historia ésta la de tantos prodigios!» 23

\footnotetext{
19 Ibidem, p. 528.

20 Ibidem, p. 533: «Après Gênes, que devint Fernand? Se rendit-il directement à Rome, qui fut son séjour dans la dernière partie de sa vie, ou demeura-t-il un temps dans d'autres villes d'Italie? Je l'ignore, mais on le saura peut-être un jour, s'il plaît aux érudits italiens d'interroger à ce sujet les archives de leur pays».

21 Ibidem, p. 530.

22 Ibidem: «on ne saurait être surpris qu'il ait cherché à se rajeunir un peu afin d'étonner encore plus le public qui se pressait à ses argumentations».

23 Ibidem, pp. 529-530.
} 
R. Poupardin (1874-1927), quien escribe casi veinte años después del inaugurador artículo de Havet, es el último erudito francés que dedica atención a Fernando de Córdoba24. También formado en la Escuela Nacional de Chartes, no se trata de un hispanista, pues su especialización se concentra en la Alta Edad Media. Como en el caso de Morel Fatio, Poupardin se sitúa conscientemente en la senda abierta por Havet. Su contribución, sin embargo, se distingue de las dos anteriores, pues se desentiende de la biografía, situándose en un plano puramente bibliográfico. De este modo, señala la existencia de dos obras -De laudibus platonis (p. 533-537) y De secretis humanae naturae per urinam cognoscendis (pp. 537-542)- en las que hasta entonces no se había reparado. El artículo se dedica exclusivamente a escribir los índices de materias -la primera consta de 44 verdades y la segunda de 47 capítulos- de ambas obras. Respecto de De laudibus Platonis, señala que debe distinguirse de aquella otra obra a la que se refiere en De omni re scibili, pues De laudibus no versa sobre la conciliación entre Platón y Aristóteles, sino que se dedica a la exaltación del primero. Al referirse a De secretis, aunque Fernando tenía el propósito de escribir dos partes 25 , recuerda que sólo se conserva la primera. De este modo, Poupardin señala un problema -segundas partes que sistemáticamente se encuentran perdidas- que afectará a muchas de las composiciones de Córdoba. En cualquier caso, Poupardin no sugerirá la hipótesis -la cual nadie se atreverá a pronunciar hasta Monfasani- de que Fernando simplemente no escribía las segundas partes que anunciaba.

\section{III}

A pesar de que la bibliografía francesa es la primera en haber realizado aportaciones científicas sobre Córdoba, el interés erudito por este autor se despierta en la misma época en España de manera independiente. Ya seis años antes del artículo de Havet, Córdoba hace acto de presencia en el epistolario de un joven Menéndez Pelayo. Mientras don Marcelino prepara su viaje a Italia, Gumersindo Laverde le da el siguiente consejo: «Me ocurre que debiera llevar V. consigo á Italia las Cartas del abate Andres, o al menos una nota de las especies que contienen relativas a Mss. españoles, entre otros el de Fernando de Córdoba De arte mirabili omnis inveniendi scibilis, que, si, como creo, no es muy largo, desearía que trajese copia de él. El tal Córdoba tiene asomos de luliano, a juzgar por el título de su obra. Segun cuen-

\footnotetext{
24 R. Poupardin, "Deux ouvrages inconnus de Fernand de Cordove" en Bibliothèque de l'École des Chartes, LXII, 1901, pp. 532-542.

25 Ibidem, p. 539: «Prima distinctio agit de signis per urinam distinctis. Secunda cum quadam varietate delectationis gratia tractat tum circa urinas tum circa ipsa generationis membra et ea quidem que generationem circumstare videntur».
} 
tan, fué un prodigio de saber. De él habla el P. Feijoo en sus Glorias de España» ${ }^{26}$. Aunque ni Gumersindo Laverde ni Menéndez Pelayo ofrecieran trabajos a la altura de los elaborados por la escuela francesa, esta breve referencia muestra la especial curiosidad que los preocupados por rescatar el patrimonio de la filosofía española sentían por este pensador. Además, sobre Fernando de Córdoba, existen abundantes juicios tanto en la Ciencia española y en De las vicisitudes de la filosofía platónica en España como a lo largo del epistolario del polígrafo santanderino. La ordenación de las referencias dispersas sobre Fernando de Córdoba mostrará -además de los juicios que sobre este pensador tuvieron Laverde y Menéndez Pelayo- el papel secundario que este pensador posee en la polémica de la Ciencia española.

En primer lugar, se debe señalar la centralidad que Gumersindo Laverde tiene como animador de los estudios acerca de Fernando de Córdoba. Aunque propiamente no comenta la filosofía de Fernando de Córdoba, a lo largo de varios años -se debe recordar, sin embargo, que el grueso de las referencias se concentran en las cartas enviadas a Menéndez Pelayo durante su viaje a Italia-, Laverde le insiste repetidamente a su discípulo en que estudie y edite a este autor «de tanto interés y trascendencia» 27 . Al lamentarse de la desidia del Estado español respecto de su patrimonio ${ }^{28}$, Laverde solicita a Menéndez Pelayo que no descuide ningún detalle sobre Fernando de Córdoba: que copie el manuscrito, que no deje huecos, que lo edite en cualquier versión, ya sea en latín o en bilingüe, ya sea en una edición de varias obras o en una monográfica. Por este interés, Laverde llega a molestarse cuando Menéndez Pelayo no transcribe íntegramente el De re omni scibile: «una vez que hace lo más, ¿por qué no hacer lo menos? Así, creo que debe usted copiar la lista de aves, peces, y que acaso interese a los naturalistas y con la que, sobre todo, teniendo completa la obra, será posible la publicacion de ésta, llenando un vacío en nuestra bibliografía y abriendo el apetito de los entendidos para que deseen saborear otros frutos de nuestra pristina filosofía.» 29

\footnotetext{
26 G. Laverde a M. Menéndez Pelayo, 10 de septiembre de 1876 en Epistolario Menéndez Pelayo, edición de M. Revuelta Sañudo, Fundación Universitaria Española, Madrid, 1982-1991, vol. 2, Carta 71, p. 148.

27 G. Laverde a M. Menéndez Pelayo, 8 de marzo de 1877, Epistolario Menéndez Pelayo, cit., vol. 2, Carta 154, p. 307.

28 G. Laverde a M. Menéndez Pelayo, 3 de marzo de 1877, Epistolario Menéndez Pelayo, cit., vol. 2, Carta 152, p. 301: «Para que esta carta no siguiese inmediatamente á la anterior y esperar á tener algo nuevo de que hablarle en ella, hé diferido unos dias mi contestacion á su muy grata de 17 del mes pasado, por lo que veo que ya está V. en la Biblioteca vaticana haciendo de las suyas, esto es, descubriendo preciosidades bibliográficas tales como los Códices de Arnaldo de Vilanova y Fernando de Córdoba. ¡Lástima que no pueda V. copiarlos, ya que no há pensado en ello nuestro Gobierno para la Biblioteca nacional!».

${ }^{29}$ G. Laverde a M. Menéndez Pelayo, 8 de marzo de 1877, Epistolario Menéndez Pelayo, cit., vol. 2, Carta 154, p. 307.
} 
Si pasamos de los incitadores comentarios de Laverde, al juicio de Menéndez Pelayo nos encontramos, en primer lugar, con una descripción general del pensamiento de Fernando de Córdoba. Además, aunque las referencias a la filosofía de Córdoba se parecen más a los comentarios aislados que los escritores españoles nunca dejaron de pronunciar desde el siglo XV que a los trabajos de los estudiosos franceses, las opiniones de Menéndez y Pelayo poseen una gran importancia, pues, sobre ellas, se solidificará la crítica española durante más de cien años. El estudioso santanderino inscribe al filósofo cordobés en la historia del platonismo -considerándolo poco platónico ${ }^{30}$ y proclive a una compatibilidad con Aristóteles ${ }^{31-}$, en la del lulismo -juzgando, sin embargo, que Córdoba no pertenece a esta corriente ${ }^{32}$ y en la de una concepción logicista de la metafísica: «principio que reduce a la unidad la muchedumbre de las diferencias [...] haciéndose así posible el sueño de una sola e indivisible ciencia, cuyas leyes se extienden a todo el mundo inteligible. Sueño ciertamente magnífico y generoso, aunque se haya de quedar en la categoría de los sueños, ya que esa ciencia trascendental y una, sólo en la mente divina existe, y sólo alcanzamos de ella, en esta vida terrenal, dispersos y múltiples reflejos. Pero si bien se mira, ¿qué es toda la filosofía, sino una aspiración más o menos frustrada, a esa síntesis suprema?»33. De esta consideración dubitativa de la lógica de Córdoba y de su aspiración a la ciencia única, nos parece que se desprende otro juicio global sobre la obra de este pensador: la de su panteísmo. Si bien los anteriores juicios -platonismo, lulismo y logicismo- marcarán la bibliografía sobre Córdoba en el siglo XX, esta consideración de Menéndez y Pelayo careció eco ${ }^{34}$. Resulta especialmente interesante que este juicio pasase desapercido, ya que se trata del primer, aunque decidido y contundente, comentario que el santanderino dedica-

\footnotetext{
30 Marcelino Menéndez y Pelayo, Ciencia española, en Id., Obras completas, Aldus-CSIC, Santander, 1953 [9 de mayo de 1877], vol. II, p. 50: «Precisamente neoplatónicos decididos no hay más que uno, León Hebreo. Fox Morcillo es en muchas cosas aristotélico, y lo mismo Fernando de Córdoba que le precedió en medio siglo».

31 Ibidem, p. 53: «Pero cuando hice aquella clasificación, no había yo examinado el manuscrito de Fernando de Córdoba, y para suponerle luliano me dejé llevar, no del título de la obra, sino de los respetables testimonios [...]. Ahora que he visto la equivocación, soy el primero en corregir el yerro». 32 Marcelino Menéndez y Pelayo, Ciencia española, en Id., Obras completas, Aldus-CSIC, Santander, 1953 [1 de mayo de 1884], vol. II, p. 370: «las vigorosas concepciones armónicas de Fernando de Córdoba, de León Hebreo, de Fox Morcillo, en quien Platón y Aristóteles, la idea y la forma se compenetran». M. Menéndez Pelayo a G. Laverde, 17 de febrero de 1877, Epistolario Menéndez Pelayo, cit., vol. 2, carta 147, p. 292: «Es obra luliana [De re omni scibile]».

33 Marcelino Menéndez y Pelayo, Ciencia española, cit., vol. II, p. 60.

34 También hace M. Menéndez Pelayo un comentario sobre la estética de Fernando de Córdoba que carecerá de influencia sobre la crítica posterior. M. Menéndez Pelayo a G. Laverde, 17 de marzo de 1877 en Epistolario Menéndez Pelayo, cit., vol. 2, Carta 157, p. 315: «Fernando de Córdoba tiene un pasaje curiosísimo sobre el arte. Puede traducirse por la fórmula moderna (que es la mía, entendida como se debe) el arte por el arte. Distingue muy bien el arte de la disciplina».
} 
ra a este autor: «Porque hay una filosofía panteísta española, resuelta y clara, que se anuncia por primera vez en Prisciliano; [...] se vislumbra en Fernando de Córdoba que en pleno siglo XV formula el principio ontológico de lo uno, en que se resuelven el ser y la nada» 35 .

Si los juicios sobre Córdoba resultan positivos -si bien limitados por la superioridad que en todo momento se concede a la cultura del siglo XVI frente a la del $\mathrm{XV}-$, existen algunas anécdotas que permiten sospechar que Menéndez Pelayo no era especialmente proclive a este autor. Además de la ya mencionada discusión provocada por no transcribir completamente el De re omni scibile, el joven estudioso no copió otro manuscrito - que todavía hoy permanece inédito-, el cual también había sido solicitado por Laverde: «Bien será que usted complete la copia de su Artificio mirabili y, si puede, la de su impugnacion de los fraterculi, para ver si podemos dar esas obras en la proyectada Biblioteca de Luis Navarro [...] donde también quisiera que se incluyesen las de Foxo»36. Pero además de no haber transcrito ni obviamente editado, como Laverde se proponía en la carta, el libro contra el fransciscanismo político, Menéndez Pelayo rápidamente se desentendió de cualquier edición de Córdoba. De hecho, nunca completo la edición de De re omni scibile que había anunciado hacer. Se puede considerar que es posible que Menéndez Pelayo no llevara a cabo este trabajo por pura limitación temporal: tantos eran sus proyectos. Sin embargo, apoya la interpretación de que al polígrafo santanderino decepcionó este autor el hecho de que contestara de la siguiente manera la pregunta de Morel Fatio acerca de la recepción del artículo de Havet. Menéndez Pelayo, tras decir cuánto le había agradado este escrito, añade: «Yo tengo preparado para la imprenta su libro inédito De artificio omnis scibilis» 37.

En conclusión, Menéndez Pelayo no puede considerarse el primer estudioso español de Córdoba. Por mediación de Gumersindo Laverde se interesó en este pensador, ofreció algunos juicios -que habrían de ser muy influyentes- sobre este pensador y esbozó un proyecto de editar algunas obras suyas -especialmente De artificio omnis scibilis - que, por motivos que no son del todo claros, jamás llevó a término. A pesar de que Córdoba nunca fuera objeto de su atención científica, las opiniones de Menéndez Pelayo sobre este pensador gozaron de una enorme influencia - directa e indirecta- la cual se podrá comprobar en las siguientes notas.

\footnotetext{
35 Marcelino Menéndez y Pelayo, Ciencia española, en Id., Obras completas, Aldus-CSIC, Santander, 1953 [13 de abril de 1877], vol. I, p. 306. Hay que advertir que la prioridad temporal del juicio de Córdoba como panteísta no es segura, ya que la edición de las obras completas de Menéndez y Pelayo no es crítica.

36 G. Laverde a M. Menéndez Pelayo, 27 de marzo de 1877, Epistolario Menéndez Pelayo, cit., vol. 2, Carta 161, p. 320.

37 M. Menéndez y Pelayo a A. Morel Fatio, 26 de abril de 1883, Epistolario Menéndez Pelayo, cit., vol. 6 , carta 87, p. 98 .
} 
Como continuador del trabajo de Menéndez Pelayo, Adolfo Bonilla y San Martín (1874-1927) es el primer español que se dedicó de modo científico y prolongado a la figura de Córdoba. El madrileño fue un estudioso sumamente prolífico, catedrático de las universidades de Valencia y Madrid. Junto a Ramón Menéndez Pidal, se trata del más importante discípulo de Menéndez y Pelayo ${ }^{38}$. Los campos en los que se prodigaron sus estudios resultan numerosos, extendiéndose desde la ciencia jurídica -su primer puesto académico fue el de catedrático de derecho mercantil- y la historia, hasta la crítica literaria, artística y la traducción. Es la faceta de historiador de la filosofía española la más rica. Fue responsable de un proyecto general sobre la historia de la filosofía española -cuya importante Wirkungsgeschichte ha sido detallada por Gustavo Bueno Sánchez ${ }^{39-}$, del cual sólo llegó a escribir los dos primeros volúmenes 40 .

Esta inconclusión, sin embargo, no le impidió escribir sobre historia de la filosofía del renacimiento español, pues, además de la monografía sobre Córdoba, publicó en 1903 Luis Vives y la filosofía del Renacimiento ${ }^{41}$, obra que le mereció la victoria en el concurso ordinario de 1901 de la Real Academia de Ciencias Morales y Políticas. Esta obra se vincula con la monografía sobre Fernando de Córdoba

38 G. Bueno Sánchez, "Historia de la "Historia de la filosofía española"”, en El Basilisco, XIII (2a época), 1992, p. 21: «En este artículo se niega que Bonilla haya sido el continuador de LaverdeMenéndez Pelayo, aunque sí lo fueran quienes se creyeron seguidores de Bonilla». En cualquier caso, el mismo M. Menéndez y Pelayo consideraba a A. Bonilla discípulo suyo. M. Menéndez y Pelayo, "Contestación" en A. Bonilla y San Martín, Fernando de Córdoba y los orígenes del Renacimiento filosófico en España, Real Academia de la Historia, Madrid, 1911, p. 26: «iY con qué efusión he de saludarla, yo que en los libros del Dr. Bonilla veo prolongarse algo de mi ser espiritual [...]! [...]Perdonadme si algo hay de inmodestia en la afirmación de este parentesco que a todos nos liga en nuestra función universitaria, pero cuando recuerdo que por mi cátedra han pasado D. Ramón Menéndez Pidal y D. Adolfo Bonilla, empiezo a creer que no ha sido inútil mi tránsito por este mundo». También ofrece el mismo juicio A. Bonilla y San Martín, Fernando de Córdoba y los orígenes del Renacimiento filosófico en España, cit., p. 21 (nota), lo que indudablemente resta verosimilitud al juicio de Bueno: «D. Pedro García, de quien conozco la siguiente obra, que posee en su Biblioteca de Santander mi maestro D. Marcelino Menéndez y Pelayo». En cualquier caso, Bueno conoce este testimonio de Bonilla, a quien Bueno considera interesado en parecer ser discípulo de Ménendez y Pelayo sin serlo. G. Bueno Sánchez, "Historia de la 'Historia de la filosofía española"”, cit., p. 40: «si aparentó hacerlo, más o menos forzado, muerto Menéndez Pelayo deshizo rápidamente el compromiso».

39 G. Bueno Sánchez, "Historia de la 'Historia de la filosofía española”, cit., pp. 21-48.

40 A. Bonilla y San Martín, Historia de la filosofia española: (desde los tiempos primitivos hasta el siglo XII), Librería General de Victoriano Suárez, Madrid, 1908 y A. Bonilla, Historia de la filosofía española: (siglos VIII-XII: judios), Librería General de Victoriano Suárez, Madrid, 1911.

${ }^{41}$ A. Bonilla y San Martín, Luis Vives y la filosofía del Renacimiento, Imprenta del asilo de huérfanos, Madrid, 1903. Hay reedición facsilimar de la Real Academia de Ciencias Morales y Políticas, Madrid, 1981. 
temática y textualmente, pues Bonilla reutilizará en la segunda párrafos de la primera. Asimismo, habla brevemente de Córdoba en las páginas preliminares de esta inicial monografía de tema renacentista: «En la corte de Alfonso V el Magnánimo, es donde mejor se echa de ver la trascendencia y significación de la reacción novísima; allí sorprendió a los entendidos la universal sabiduría de un Fernando de Córdoba» 42 . También en el campo de la filosofía del siglo XV Bonilla editó dos obras de Ferrán Núñez, el Tratado de amiçiçia ${ }^{43}$ y el Tratado de la bienaventurança, donde volvería a expresar un juicio negativo acerca de la filosofía de esta centuria: «no precisamente en los renacientes, sino en los aspirantes a renacientes del siglo XV». Con el escrito sobre Fernando de Córdoba y la edición de De artificio omnis investigandi et inveniendi natura scibilis, Bonilla no sólo completa el proyecto de Menéndez y Pelayo, sino que le sirve como discurso de entrada en la Real Academia de Ciencias Históricas y Morales. La conexión con Menéndez Pelayo con este trabajo resulta todavía más estrecha pues el estudioso montañés responde este discurso de entrada.

Alejada del interés biográfico de los estudiosos franceses, Bonilla justifica su trabajo a través de argumentos netamente filosóficos. Su estudio surge de la intersección de dos amplias consideraciones teóricas. En primer lugar, Bonilla se remite a la doctrina según la cual, entre la filosofía y su historia, existe una relación absolutamente esencial: «La base del razonamiento filosófico es una indagación histórica»44. De este modo, estudiar a Fernando de Córdoba le conducirá directamente a un problema de naturaleza filosófica. ¿Cuál es esta cuestión? El filósofo cordobés aparece como un defensor de una determinada propuesta lógica, la cual considera que existe una teoría causal general, que explica todas las causas y de este modo, al no ser la ciencia más que el estudio de las causas, las ciencias particulares 45 . Por tanto, la puerta por la que Bonilla accede a este pensador es la de la lógica, cuya obra fundamental, De re omni scibili, transcribe en apéndice (pp. IIILXXX), en lo que hasta la fecha constituye la principal edición de este autor.

\footnotetext{
42 A. Bonilla y San Martín, Luis Vives y la filosofía del Renacimiento, cit, p. 30.

43 A. Bonilla y San Martín, "Ferrán Núñez: Tractado de amiçiçia", Revue hispanique, XIV, 1906

44 A. Bonilla y San Martín, Fernando de Córdoba y los orígenes del Renacimiento filosófico en España, cit., p. 11. Ibidem, pp. 10-11: «pero lo que no puedo aceptar es que un pensador discurra provechosamente acerca de cualquier problema filosófico, sin conocer por lo menos los principales esfuerzos de los que le han precedido. Allá a solas con su cabeza, ese pensador correría gravísimo peligro de descubrir lo que de coro sabe cualquiera que haya saludado un manual de historia filosófica, y emplearía un esfuerzo inútil en reconstruir lo ya edificado».

45 Ibidem, p. 14: «Según se conteste afirmativa ó negativamente a la pregunta, el valor de la disciplina lógica variará de un modo extraordinario; porque, afirmada la existencia del objeto lógico, el sujeto se hallará en potencia propincua para utilizar un artificio casi divino, verdadera piedra filosofal, con la cual podrá investigar y demostrar, de un modo universal y absoluto, todo lo que se puede saber en todas las ciencias; y si se contesta negativamente, habrá que invertir el orden genético que habíamos supuesto, y lejos de ser la prueba especial una derivación de la general, será ésta una consecuencia de aquélla».
} 
A pesar del interés fundamentalmente filosófico y quizá por la circunstancia académica del escrito, Bonilla realiza un excurso, que se extiende de la página $15 \mathrm{a}$ la 43, por el concepto de Renacimiento y por la filosofía de este periodo. También se ofrece una larga biografía sobre Fernando de Córdoba, que va de la página 43 a la 86. Tras esta extensa introducción, se ofrece un recuento de las obras escritas por Fernando de Córdoba, incluyendo aquellas que se encuentran perdidas. A pesar de la longitud del estudio biográfico, Bonilla se limita a reproducir los datos hallados por los estudiosos franceses, traduciendo alguno de los documentos al castellano y contextualizándolos dentro de un panorama cultural hispánico más amplio. Sin embargo, con excepción de la referencia al Diálogo de vida beata de Juan de Lucena en la que se cuenta cómo el rey Federico de Hungría queda maravillado de la precoz sabiduría de Córdoba, no se ofrece ningún dato biográfico nuevo ${ }^{46}$. Concluidas estas dos introducciones, comienza la sección filosófica, que es la más rica del estudio.

¿Qué dice Bonilla sobre la filosofía de Córdoba, especialmente sobre la cuestión de lógica en la que se centra el trabajo? Desde el punto de vista filosófico, la solución que Fernando de Córdoba propone no le convence: «leyendo dicho tratado sin entusiasmos ni prejuicios, si bien se adquiere la convicción de que Fernando de Córdoba debió de ser persona de no vulgar talento y dialéctico de extraordinaria agudeza, persuádese uno asimismo de que su obra es un arte de palabras, y de que su cacareado Artificio es una invención más aparente que sólida y fructífera» 47 . Esta imagen decepcionante de Córdoba, que constituirá uno de los Leitmotive del retrato, se extiende al juicio sobre otros aspectos de su pensamiento.

Continuando esta imagen negativa, no lo considera un filósofo renacentista, sino tan sólo un precursor ${ }^{48}$, pues su formación permanece en el Medioevo: «la erudición tan medieval como cuando nuestro héroe estuvo a punto de ser condenado en París y tostado en Colonia»49. Se insiste en que nunca aprendió bien latín - «la latinidad es deficiente»-, incumpliendo la recomendación de Valla ${ }^{50 .}$ Coherentemente con esta imagen, se juzga que, a pesar de haber escrito dos obras de tema platónico, su devoción por Platón no va más allá de lo superficial: «Pero este platonismo no ha encarnado en él por completo, porque sigue siendo, en el fondo de su mente, un aristotélico, y por añadidura, un escolástico, más próximo a Pedro Hispano que a Tomás de Aquino» ${ }^{51}$. Esta contradicción entre el propósito y

\footnotetext{
46 Ibidem, p. 77. Se debe recordar que Bonilla no señala explícitamente el hallazgo de esta fuente.

47 Ibidem, p. 122.

48 Aunque no se puede considerar ambigua, la monografía de Bonilla contiene frases que podrían pensar que lo consideraba renacentista. Ibidem, p. 106: «No olvidéis, señores, que Fernando de Córdoba, como Fausto, es hombre del Renacimiento».

49 Ibidem, p. 104.

50 Ibidem.

51 Ibidem. Un juicio similar en Ibidem, p. 122: «es más bien un aristotélico que un platónico».
} 
la realidad se cumple también en su relación con Raimundo Lulio. Aunque critique y quiera separarse del filósofo mallorquín ${ }^{52}$, Córdoba «es en sustancia un nuevo partidario de Lulio» 53 . En definitiva, nuestro filósofo le decepciona, se trata de alguien que prometía mucho, pero ha cumplido poco.

Este parecer se extiende a la misma cantidad de obras escritas. A pesar de que Bonilla atribuye a Córdoba la composición de catorce obras, considera que su producción resulta escasa: «Parece ésta, desde luego, una producción harto exigua para la nombradía de Fernando de Córdoba. Si sus dotes eran tan extraordinarias como la tradición nos la pinta, había derecho a esperar algo más de tan celebrado varón» ${ }^{54}$.

Por otra parte, esta visión crítica del personaje coincide con una evaluación notablemente negativa de la filosofía de este periodo, de cuyas faltas y limitaciones Córdoba aparecería como emblema 55 . La filosofía española del siglo XV se caracteriza por una fundamental incomodidad lingüística. Por un lado, se admiran las lenguas clásicas y se quieren rescatar las grandes obras de esta tradición cultural. Por otro, aunque el latín es fluido -aunque no en el caso de Córdoba-, muy pocos saben el griego ${ }^{56}$. En suma, esta admiración a las lenguas clásicas conduce a un juicio excesivamente severo de la lengua vernácula ${ }^{57}$, así como un estilo demasiado latinizante al emplearla 58 . 52 Ibidem, p. 106: «Y, en cuanto a Lulio, endereza contra él una larguísima diatriba, diciendo que es
tan largo en prometer como tacaño en dar; que todo lo confunde y baraja sin criterio ninguno; que, sin
saber hablar, pretende enseñar elocuencia; que, en la Dialéctica, fuera de lo que tomó de Aristóteles,
lo demás que escribe es inepto y propio de un loco furioso; que su Ars magna es una ridícula fuente
de risibles arroyuelos; que su estudio ha hecho que algunos fuesen encerrados en manicomios, y en
suma, que Lulio fué varón desprovisto de todo género de letras, sino que por razón de su humor melan-
cólico tuvo elevado ingenio, circunstancia peligrosísima cuando se junta con la carencia de erudición».
53 Ibidem, p. 122. También, aunque el juicio se repite en otros lugares, en Ibidem, p. 127: «En todo el
libro De artificio reina el espíritu de Lulio, con sus defectos y sus grandezas. Aun en las ocasiones en
que se separa del modelo, late el recuerdo de éste».

54 Ibidem, p. 103.

55 Esta imagen negativa de Bonilla de la filosofía del siglo XV se reproduce en T. Carreras y Artau y J. Carreras y Artau, Historia de la filosofía española. Filosofía cristiana de los siglos XIII al XV, Asociación española para el progreso de las ciencias, Madrid, 1943, quienes citan con profusión a Bonilla. Por ejemplo, Ibidem, vol. II, p. 641: «El procedimiento adoptado contribuye a hacer más ingrato el estilo, ya de sí algo fatigoso. Como dice muy bien el señor Bonilla, estos dos opúsculos de Ferran Núñez constituyen una buena muestra de lo que eran la erudición y el estilo, "no precisamente en los renacientes, sino en los aspirantes a renacientes del siglo XV"».

56 A. Bonilla y San Martín, Fernando de Córdoba y los orígenes del Renacimiento filosófico en España, cit., p. 26: «a excepción de Don Alonso de Cartagena, de Don Enrique de Aragón y de don Juan Margarit, apenas ningún otro de los literatos de aquella época, llegó a tener conocimiento del idioma griego».

57 Ibidem, p. 31: «Esta veneración hacia las lenguas clásicas, iba acompañada en algunos literatos de excesivo menosprecio respecto de las vulgares. Así el Doctor Ferrán Núñez, del Consejo Real y médico del Duque del Infantado, dedicando a éste su opúsculo: Tractado de Amicieia, se lamenta de ejercitar su balbuciente lengua». C. Alvar, "La traducción en Castilla en el siglo XIV" en Versants, LV, 2008 , p. 143-144, da una imagen completamente positiva del siglo XV, aunque no se refiera explíci- 
A pesar de este recuerdo -quizá precisamente por él- de la inseguridad lingüística de los pensadores españoles del siglo $\mathrm{XV}$, reconoce que el humanismo se implanta sólo en el siglo siguiente en España, donde, sin embargo, todavía existirán detractores ${ }^{59}$. Junto con Hernán Nuñez Pinciano y Arias Barbosa, Nebrija es el principal responsable de haber sacado de este atraso a España, en la que habría introducido los conocimientos aprendidos en Italia: «La revolución en este orden se halla principalmente representada por Elio Antonio de Lebrija, que, después de respirar durante dos lustros la atmósfera del Renacimiento italiano, volvió a España con ánimo de desterrar la barbarie antigua y de sustituir los Perottis y los Pastranas por nuevos y más científicos trabajos, empresa a cuya realización fue alentado por el ilustre don Alonso de Fonseca, arzobispo de Sevilla» 60 . El Renacimiento -concepto burckhardtianamente idealizado en Bonilla- sólo llegará a España en el XVI.

Este juicio negativo sobre Córdoba y el pensamiento español del siglo XV resulta especialmente llamativo por el contexto general en que esta obra se introduce, así como por el papel que Bonilla y San Martín representa en esta polémica de la ciencia española61. En la página 70, hay un detalle -el autor se alegra de que Córdoba fuera perseguido en París, de tal manera que no se pueda acusar a las instituciones españolas de intransigentes ${ }^{62}$ - que permite apreciar que, en las primeras décadas del siglo XX, la cuestión de la ciencia española era candente. En la introducción de esta monografía, Bonilla repite muchos de los argumentos con los que

tamente a la filosofía, sino al de la traducción: «la incapacidad de las Universidades y el desinterés de la corte por la tradición científica árabe, sumados a la inestabilidad política hicieron que el siglo XIV se convirtiera en un período de crisis también en el mundo de la traducción. [...] El paso del siglo XIV al XV marca un cambio profundo, que se puede ejemplificar en las figuras de D. Pedro López de Ayala (1331-1407) y de Ínigo López de Mendoza, marqués de Santillana (1398-1458); ambos mantienen una estrecha relación con el mundo de los libros y con la tradición literaria del resto de Europa, pero el Canciller representa el final de una nueva época, mientras que el Marqués inicia un período nuevo».

58 A. Bonilla y San Martín, Fernando de Córdoba y los orígenes del Renacimiento filosófico en España, cit., p. 30.

59 Ibidem, p. 34: «Algún tanto remisa anduvo España, sin embargo, en obedecer a la tendencia por el humanismo representada (aunque con cresces indemnizó este retraso durante el siglo XVI), y preciso es reconocer también que, una vez instaurada en nuestra patria -a lo cual contribuyeron no poco los esfuerzos de los erasmistas- todavía hubo algunos rutinarios e indolentes».

60 Ibidem, p. 34.

${ }^{61}$ La superioridad de la filosofía y en general de la cultura española del siglo XVI sobre cualquier otracenturia -incluido obviamente el siglo XV- es una de las doctrinas más nucleares de los defensores de la Ciencia española. M. Menéndez y Pelayo, "Respuesta”, cit., p. 23: «Con Luis Vives había penetrado el Sr. Bonilla en las entrañas de nuestra Filosofía durante el período en que mostró mayor pujanza, y en que su voz fué más oída en el mundo»

62 A. Bonilla y San Martín, Fernando de Córdoba y los orígenes del Renacimiento filosófico en España, cit., p. 70: «¡Válame Dios! [...] i[Y] cuán agradecimos debemos estar a la Providencia porque fuese la universidad de París y no una de España, la que explicase por artes de brujería el mucho saber de Fernando de Córdoba, y la que persiguiese y detuviese, como después molestó y persiguió a Erasmo! [...] Cuando hay quien dice ahora, que España volvió la espalda al Renacimiento, ¿qué no se diría si tales hechos hubiesen ocurrido en tierra de Castilla?». 
Menéndez Pelayo había defendido la existencia y la importancia de la filosofía española. Engrandece a Fox Morcillo, quien alcanzaría la cima en el problema de la conciliación entre Platón y Aristóteles ${ }^{63}$, y a Vives, «el mismo Renacimiento no tiene otro filósofo más completo ni representativo» ${ }^{64}$.

El tono polémico, aunque sin duda más velado que en los artículos de Menéndez Pelayo, Perojo o de la Revilla, recorre Fernando de Córdoba y los orígenes de la filosofía del Renacimiento. Bonilla se mofa de la superficialidad de aquellos estudiosos -fácilmente identificables con quienes negaban valor a la filosofía española- que quedan obnubilados ante la última moda extranjera. Esta pasión los lleva inevitablemente a quedar en ridículo: «Bien es verdad que en nuestros propios días se ha afirmado algo análogo, por haber sustituido el alemán al tipo de lengua filosófica que antes existía; y como si Alejo Venegas, Pedro Simón Abril, Fray Luis de León y toda la inmensa falange de nuestros místicos se hubiesen ocupado en el arte de cocina, y no en las más elevadas especulaciones, oigo decir a los Meistersinger de ahora que el castellano no es apto para expresar debidamente los conceptos metafísicos» ${ }^{65}$. Este afán extranjerizante de los negadores del patrimonio filosófico español no sólo es posible motivo de sonrojo, sino que esta obsesión por lo foráneo -profundamente enraizada en el espíritu cultural español- sería responsable del retraso intelectual patrio: «La decadencia ha venido después, y hoy es verdaderamente aterradora, por lo mismo que hemos abandonado la casa propia, que es la tradición, y vivimos sin hogar y sin rumbo, pensando no más europeizarnos, como si no fuese menester españolizarnos primero, o lo que es lo mismo, tener fe en la virtualidad del propio esfuerzo antes de reclamar el complemento del ajeno» ${ }^{66}$. Bonilla, sin embargo, parece no percibir que esta tendencia de la élite cultural española de beber y formarse en fuentes extranjeras es una tradición muy anterior a los krausistas y que ya puede comprobarse en figuras del XV como Nebrija o, en cierta medida, el mismo Córdoba.

63 Ibidem, p. 133: «El intento más científico de conciliación entre Platón y Aristóteles es el del español Sebastián Fox Morcillo, en su áureo libro De naturae Philosophia, seu de Platonis et Aristotelis consesione».

64 Ibidem, p. 135. El mismo Menéndez y Pelayo, "Respuesta", cit., p. 13, caracteriza de modo muy similar al filósofo valenciano: «Luis Vives, el representante más completo de la filosofía crítica del Renacimiento en cualquier país de Europa».

65 Adolfo Bonilla y San Martín, Fernando de Córdoba y los orígenes del Renacimiento filosófico en España, cit., p. 31.

66 Ibidem, p. 135. Es interesante notar que Bonilla no relaciona a Nebrija -en tanto que importador de modas culturales extranjeras- con aquellos contemporáneos que, obsesionados por escuelas foráneas, minusvaloran las humanidades y costumbres españolas. Hay que recordar que M. Menéndez y Pelayo, "Contestación", cit., p. 3, ensalza a Bonilla por su formación patria: «mucho tendrían que aprender en el ejemplo de catedráticos como éste, formados sin salir de España, discípulos primero y maestros luego». 
Ya se ha señalado que en Menéndez y Pelayo podría existir una cierta ambivalencia en su juicio sobre Fernando de Córdoba. Esta ambivalencia se agudiza en el caso de Bonilla, cuyo desagrado puede explicar por qué Menéndez y Pelayo incumpliera la promesa de edición. A pesar del deseo de rescatar y enaltecer la tradición filosófica española, ni Menéndez y Pelayo ni Bonilla descubren en Córdoba a alguien que satisfaga sus ambiciones. De este modo la figura de Fernando de Córdoba impone una reflexión sobre los límites que la filosofía y la ciencia española -al menos la del siglo XV-tiene para aquellos que son sus máximos defensores.

El carácter matizadamente negativo de la monografía de Bonilla no puede ser el único responsable de que durante más de ochenta años nadie le dedicara a Córdoba un libro, siendo verdaderamente escasos los estudios especializados sobre su pensamiento. La ausencia de trabajos importantes sobre Fernando de Córdoba entre la monografía de Bonilla y la de Monfasani permite el uso de las palabras con que Bueno Sánchez describía ciertos problemas de la historiografía de la filosofía española para el caso de nuestro filósofo: "Y esto ocurre, en general, tanto en la 'Historia de la Filosofía española' como en la 'Historia de la historia de la filosofía española': se hacen libros sobre libros que tampoco han visto las fuentes, como si hubiera cierto reparo en ir a las reliquias y a los relatos, amparándose en referencias a una cada vez más copiosa historiografía que se ha ido construyendo por métodos similares» ${ }^{67}$. En el caso de Córdoba, resultan bastante sencillos de entender «los reparos de ir a las reliquias», pues, como ya se ha recordado, el grueso de sus obras -situación que permanece inalterada- estaban sin editar y escritas en latín. Por otra parte, si no se visitan las reliquias de Córdoba, la bibliografía en este tiempo no se cansa de nutrirse -para rechazarlas o aceptarlas- de las opiniones de Menéndez y Pelayo.

Se puede afirmar que, salvo excepciones que serán señaladas, la bibliografía sobre Fernando de Córdoba no acude a los textos. Por otro lado, la atención durante estos ochenta años se concentra principalmente en la consideración de las fuentes de Córdoba y del movimiento espiritual al que pertenece. De este modo, los estudiosos estarán preocupados de señalar si Córdoba es renacentista o medieval -lo que en algún casos se identifica con si es platónico o no- y de establecer su relación con Lulio. Por otra parte, será común la queja por la escasez de datos de la biografía de Córdoba, sin que esto, sin embargo, lleve a los estudiosos a consultar los archivos, en busca de nuevos documentos y fuentes.

67 G. Bueno Sánchez, "Historia de la 'Historia de la filosofía española”, cit., p. 22. 
Si no consideramos que Bonilla es el único responsable de la desatención por Fernando de Córdoba, sí que se le puede atribuir la paternidad de que este pensador ocupe un puesto de honor en las historias de la filosofía española. Como Bueno Sánchez ha recordado, Adolfo Bonilla influye, a través de su programa para la historia de la filosofía española, en la inclusión de Córdoba en las historias generales de los Carreras y Artau y Abellán68. De este modo, nuestro pensador cerrará el segundo y último volumen de la Historia de la filosofia española. Filosofía cristiana de los siglos XIII al XV de 1943 de los hermanos Carreras y Artau. La opinión que transmite este manual sigue las líneas directrices de Bonilla. Se da una imagen negativa de la filosofía del periodo, a la que sólo Córdoba podría haber redimido. Lamentablemente esta salvación no la habría podido consumar: «Tan sólo un genio precoz $[\ldots]$ presagió una figura de auténtico pensador, que pudo influir en la marcha del pensamiento filosófico europeo» 69 . En tanto que decepción, Córdoba vuelve aparecer como el portaestandarte de la filosofía y de la cultura del siglo XV70.

Ya a fines de los 70, en la Historia crítica del pensamiento español, Abellán lo sitúa como el primer platónico de España. Nuevamente, en las referencias -aunque más escasas que las de los hermanos Carreras y Artau- quedan marcadas por la sombra de Bonilla y Menéndez Pelayo. Abellán considera, en primer lugar, que a través de Córdoba el Renacimiento napolitano influye en España, consideración ciertamente equívoca en la medida que no tenemos noticia de un hipotético regreso o visita a España, ni de que los manuscritos o libros de Córdoba circularan por España, ni siquiera podemos estar seguros de que la personalidad intelectual de nuestro pensador fuese acorde al espíritu del Renacimiento napolitano ${ }^{71}$. También

68 G. Bueno Sánchez, "Historia de la 'Historia de la filosofía española”", cit., p. 47: «El proceso iniciado el $1^{\circ}$ de mayo de 1927, cuando Marichalar ofreció públicamente sus medios para que [...] continuase el inacabado proyecto de Bonilla [...] culminó treinta años después [...]: en 1939 y 1943 se publicaron los dos tomos de Carreras Artau [...]: en 1941 los tres tomos de Solana, dedicados a la época del Renacimiento y en 1957 [...] los dos tomos que Cruz Hernández dedicó a la filosofía hispano-musulmana».

69 T. Carreras y Artau y J. Carreras y Artau, Historia de la filosofía española. Filosofía cristiana de los siglos XIII al XV, cit., vol. II, p. 642.

70 Ibidem, p. 649: «Fernando de Córdoba es un vivo ejemplo de la indecisión característica del Prerrenacimiento español del siglo XV, que oscila entre la vieja cultura medieval y el nuevo espíritu humanista. Enamorado de los modelos clásicos, conserva todavía la sustancia del pensamiento anterior; su platonismo es mera pátina superficial, en la que las preocupaciones nuevas afloran sobre un mundo de ideas y preocupaciones en gran parte medievales. Lo mismo podríamos decir, aun con mayor razón, de Alonso de Cartagena, de Pedro Díaz de Toledo, de Juan de Lucena».

71 J. L. Abellán, Historia crítica del pensamiento español. Tomo I: Metodología e introducción histórica, Espasa, Madrid, 1979: «La influencia de la corte napolitana, aunque amortiguada, no dejó de sentirse en Castilla a través de hombres como Alfonso de Madrigal el Tostado, el Marqués de Santillana, Fernando de Córdoba, Jerónimo Pau, el príncipe de Viana». También los juicios de G. Díaz Díaz, Hombres y documentos de la filosofia española, CSIC, Madrid, 1983, vol. II, pp. 392-396, son sumamente parecidos a los de Abellán, si bien Díaz Díaz se mantiene más fiel al criterio de Bonilla, que 
considera que De re omni scibili es la obra más importante de Córdoba ${ }^{72}$. Desde el punto de vista de las fuentes, juzga - esta vez de modo más decidido que Bonillaque Fernando de Córdoba es un verdadero platónico. Abellán lo sitúa entre los platónicos españoles del XVI73, lo considera incluso un predecesor de León Hebreo, aunque, al mismo tiempo, su personalidad intelectual queda principalmente marcada por el lulismo ${ }^{74}$. En la consideración general sobre la personalidad intelectual de Córdoba, Abellán -que lamentablemente tampoco conoce las fuentes- sigue literalmente el juicio de Bonilla 75 .

Si pasamos de las historias generales a los estudios más especializados, se debe otorgar a Batllori un lugar preeminente y excepcional en estos ochenta años. Por un lado, en un artículo de 1958 - "El gran Cardènal d'Espanya i el lul· lista antilul· lià Fernando de Córdoba"76 - ofrece un precioso y pequeño detalle sobre la biografía de nuestro personaje. El papa Sixto IV, a través del cardenal de Toledo, Pedro González de Mendoza, solicita a los Reyes Católicos que concedan a Fernando de Córdoba un obispado, petición que, sin embargo, no satisfarían. También en su recopilación de artículos, Humanismo y Renacimiento 77 , vuelve brevemente sobre esta figura. Como en el 58, insiste en el carácter contradictorio de la relación de Fernando de Córdoba con Raimundo Lulio ${ }^{78}$. Respecto de la relación con el platonismo, insiste en considerar a Fernando de Córdoba -lo que, para él, caracteriza a la filosofía hispánica en su conjunto- no tanto un exaltador de Platón como un conciliador de los dos grandes filósofos 79 . Esta idea que, a pesar de tener cierta influen-

insistía en el carácter escolástico de la formación de Fernando de Córdoba. Ibidem, p. 393: «Su saber, empero, juzgado a la luz de los más ecuánimes testimonios de la época y a través de sus escritos mismos, se caracterizaba, dentro de su indudable vastedad, por su circunscripción a los tiempos áureos de la escolástica y a la Biblia, con manifiesta indigencia, al menos en el momento de abandonar la Península, tanto del mundo clásico, como del pensamiento helenista y patrístico».

72 J. L. Abellán, Historia crítica del pensamiento español. Tomo II: La edad de Oro, Espasa, Madrid, 1979, p. 134: «La obra suya más importante es De artificio omnis et investigandi et inveniendi natura scibilis».

73 Esta insistencia en el platonismo ha podido influir en el breve comentario que a Fernando de Córdoba dedica A. Guy, La philosophie espagnole, PUF, París, 1995, p. 26: «On rencontre aussi un platonisme de haut vol chez Fernando de Córdoba».

74 J. L. Abellán, Historia crítica del pensamiento español. Tomo II: La edad de Oro, p. 135: «si grande es en él la influencia de Platón, más grande aún es la de Ramón Llul».

75 Ibidem, p. 136.

76 M. Batllori, "El gran Cardènal d'Espanya i el lul lista antilul lià Fernando de Córdoba" en Estudios lulianos, II, 1958, pp. 313-316.

77 M. Batllori, Humanismo y Renacimiento. Estudios hispanoeuropeos, Ariel, Barcelona, 1987.

78 Ibidem, p. 15: «El Arte luliano, la combinatoria, ofrecía al nuevo período de la cultura una posibilidad de encontrar la unidad de las ciencias, un método que, sin saberlo, seguían aquellos, que como Fernando de Córdoba y Agrippa von Nettesheim, condenaban el propio Arte luliano para volver, en el fondo, a sus métodos apriorísticos».

79 Ibidem, pp. 34-35: «La ausencia de una decidida fractura con la tradición medieval determinó que en España no hubiese una escuela platónica semejante a la de Ficino en Italia y paralela a aquella serie 
cia bibliográfica, no se sostiene sobre una base segura -seguridad que, sin embargo, han compartido muchos estudiosos españoles desde Menéndez y Pelayo-, pues su origen debemos situarlo en el desaparecido De duabus philosophiis et praestantia philosophiae Platonis supra Aristotelis y no en el conservado De laudibus Platonis.

En el mismo año en que el historiador de la teología Melquíades Andrés hablaba de la necesidad de devolverle a Córdoba un poco de atención -«autor cultísimo, merecedor de una monografía» 80 , se encuentran en la obra de Ottavio di Camillo, El humanismo castellano del siglo $X V$, el mayor número de páginas dedicado a este pensador durante estos ochenta años. Camillo, quien al igual que Andrés considera que es una figura poco estudiada ${ }^{81}$, se quiere separar de la lectura renacentista que habría promovido Bonilla y San Martín. Esta imagen de la aproximación de Bonilla resulta del todo errada. Baste recordar que Bonilla -como ya ha sido recordado- lo emparenta espiritualmente con Pedro Hispano o Tomás de Aquino82. El juicio de Camillo vuelve a resultar llamativo, pues, después de haber afirmado que fuera «un hombre refractario al humanismo», lo califica simultáneamente como exaltadamente platónico: «Pero ni Bessarión ni Trapezuncio convirtieron a los filósofos griegos en cristianos, conscientes siempre de su paganismo. Fernando de Córdoba, por otra parte, prefiguró a Cristo en Platón, llegando a tomar literalmente el epíteto de divino y en la tercera, quinta y sexta veritates trata de probar el nacimiento sobrenatural del filósofo» 83 .

Antes de cerrar esta poco prolífica época para la bibliografía de Córdoba, hay que resaltar una contribución que se produjo a finales de los años cuarenta, especialmente valiosa, pues ofrece la última edición de una obra completa de Fernando de Córdoba. El estudioso frances Léon Baudry en su estudio, La querelle des futurs contingents (Louvain 1465-1475), edita el tratado de Fernando de Córdoba sobre esta cuestión ${ }^{84}$. Para la figura de Fernando de Córdoba -sobre éste, poco más dice

de comentadores del Estagirita a la que acabamos de aludir. Hubo, en cambio [... ], un constante deseo de coordinar el pensamiento platónico con el de Aristóteles: lo hemos visto durante el Cuatrocientos, en Fernando de Córdoba; y lo volvemos a hallar, a mediados del siglo XVI, en el sevillano Sebastián Fox Morcillo (1528-1560)».

80 M. Andrés, La teología española en el siglo XVI, cit., vol. I, p. 296 (en nota).

81 O. di Camillo, El humanismo castellano del siglo XV, traducción de M. Lloris, Fernando Torres Editor, Valencia, 1976, p. 235: «Mucho nos ilustraría una mayor investigación sobre este punto. Al parecer, el tratado de Fernando tuvo un impacto, pues según nos informa Kristeller, años más tarde el hijo de Trapezuncio quiso defender a su padre de los ataques del autor español».

82 Este autor afirma - de modo completamente impreciso- que Bonilla y San Martín «no alcanza a ver que los intereses intelectuales de este autor no coinciden con los de Valla y el resto de los humanistas» (Ibidem, p. 236).

83 Ibidem, p. 235.

${ }^{84}$ L. Baudry, La querelle des futurs contingents (Louvain 1465-1475), Vrin, París, 1948. El tratado de Fernando de Córdoba se encuentra en pp. 134-170. 
Baudry aparte de que el tratado surge a petición de Besarión y que el cordobés pertenecía a la comisión que juzgó a Pedro Rivo-, el interés fundamental de este trabajo consiste en haber publicado uno de los manuscritos de Córdoba.

Sin duda, la bibliografía sobre Fernando de Córdoba alcanza el nivel científico más elevado con la publicación de John Monfasani, Fernando of Cordova. A Biographical and Intellectual Profile, publicada en 1992. Monfasani, profesor de historia en la Universidad del Estado de Nueva York en Albany, se cuenta entre los historiados de la filosofía del Renacimiento más importantes. Ha dedicado una monografía a Jorge de Trebisonda y recientemente ha editado una obra sobre su maestro, el pionero de la filosofía del Renacimiento Paul Oskar Kristeller. Fernando de Córdoba le interesó inicialmente como protagonista de una de las polémicas más relevantes del periodo: «Mi interés por Fernando nace de su participación en la controversia sobre Platón y Aristóteles en la Italia del siglo $X V_{\gg}{ }^{85}$. De este modo, anuncia una edición de De laudibus platonis, que se incluirá en un estudio general sobre esta controversia definidora del pensamiento del siglo XV86.

A pesar de que el contacto con Córdoba se produce en relación con esta particular polémica, Monfasani no se limita a explicar la postura de Córdoba en el debate - de hecho la atención dedicada a esta cuestión resulta relativamente escasa-, sino que analiza globalmente la vida y la obra de este pensador. Hay tres notas que definen este retrato: Córdoba como representante de la cultura universitaria española del siglo XV, como autor polifacético y como poseedor de una biografía que atrajo la atención de su tiempo ${ }^{87}$. Ciertamente, gracias a este trabajo, Córdoba se extiende sobre campos en los que la bibliografía anterior no había prodigado ningún detalle, aparte de señalar, como mucho, el título de alguna obra. La disputa acerca de la formación y las preferencias intelectuales no se limita a considerar a Córdoba como renacentista o medieval, luliano o antiluliano. Esta aproximación introduce el pensamiento de Córdoba en nuevos campos como la política, la eclesiología y las cien-

\footnotetext{
85 J. Monfasani, Fernando of Cordova. A Biographical and Intellectual Profile en Transactions of the American Philosophical Society, Volumen LXXXII, Parte 6, The American Philosophical Society, Philadelphia, 1992, p. 1.

86 Ibidem, p. 24: «will be part of my forthcoming study on the Plato-Aristotle controversy». Este estudio general, así como la edición, todavía no se ha publicado.

87 Ibidem, p. 1: «But his significance extends beyond the controversy. He is a major representative of Spanish university culture in the first half of the fifteenth century. His philosophical, theological, and scientific writings cover a wide range of topics important to his age. And his biography has a special value because of what he did and whom he impressed in his travels in the cities, courts, and universities of Europe».
} 
cias médicas. Del mismo modo, sus fuentes se ven enriquecidas con nuevas dependencias y relaciones.

Como ocurría con los primeros estudiosos franceses, la actitud ante Fernando de Córdoba es eminentemente positiva. Monfasani recuerda cómo muchos estudiosos se han sentido decepcionados ante una figura que, desde su primera aparición pública, aparecía colosalmente prometedora ${ }^{88}$. Para Monfasani, en cambio, no hay decepción ni desengaño, sino que la continuidad sella la evolución de su obra: «Los académicos se han lamentado el fracaso de Fernando por no haber estado a la altura de la brillante promesa de su juventud. Pero existe una cierta continuidad entre el Wunderkind de la década de 1440 y el curialista desenvuelto de la de $1460 » 89$.

Aunque la aproximación general de Monfasani resulta sumamente positiva, la misma frase con la que se abre la monografía - «en parte charlatán, en pate Wunderkind, en parte escolástico ilustrado»- advierte que su retrato estará exento de alabanza. De hecho, Monfasani informa de una serie de actitudes que restan simpatía al joven que disputaba en las cortes europeas. En esa descripción, Córdoba aparece como alguien pagado de sí mismo. No tiene problemas en considerarse en sus dos obras editadas en vida como «famosísimo en todo el mundo» ${ }^{90}$. La exhibición de cualidades, que inevitablemente marca sus disputas públicas, se acompaña de una exaltación de sus capacidades. Son estas exageraciones las que están detrás de las contradicciones de los documentos que informan acerca de su fecha de nacimiento ${ }^{91}$. Esta reevaluación de las fuentes, junto con otra serie de argumentos, conduce a Monfasani a considerar que la fecha de nacimiento debe retrasarse de 1426 a 142192 . No sólo exagerado -Monfasani utiliza dos veces la palabra braggadocio para caracterizar este exhibicionismo 93 -, Córdoba es un pensador que trabaja aceleradamente, despreocupado de la exactitud de las referencias que utiliza ${ }^{94}$. Esta

88 Esta inclinación -especialmente marcada en el caso de Bonilla- es característica de la aproximación de la bibliografía española a la figura de Córdoba. Ansiosa por encontrar una figura que otorgue definitivo lustre a la filosofía española, la historiografía hispánica queda decepcionada ante una figura intermedia y considerable, pero que no puede ser comparada con los grandes representantes de la filosofía del siglo XV como Nicolás de Cusa, Giovanni Pico della Mirándola o el propio Besarión.

89 Ibidem, p. 3.

90 Ibidem, p. 50.

91 Ibidem, p. 7: «Obviusly, we should take Fernando's assertions cum grano salis».

92 Ibidem, p. 5: «Finally, we have several papal documents of 1448 and 1449 concerning benefices for him where no mention is made of his being under canonical age for priesthood (twenty six completed years) and therefore in need of any dispensation. This silence suggests that Fernando was twenty-six years old by 1448 and not in need of any dispensation». Ibidem, p. 5: «even if we asume, as I think we ought, that Fernando exaggerated his youthfulness to amaze his his audiences even further». Esta postura ya había sido defendida por Havet.

93 Ibidem, p. 8 y p. 50.

94 Ibidem, p. 21 (nota): «Another characteristic which the Viennese propositions reveal is Fernando's sloppiness in citing his authorities». Ibidem, p. 28: «he worked very rapidly. Consciously or unconsciously, when citing authors, he did not always distingish memory from fancy». 
inexactitud, junto con la exageración, lleva a Monfasani a creer que en obras en las que se anuncian segundas partes, éstas nunca llegaron a escribirse, como por ejemplo ocurre con De iure medios exigendi fructus ${ }^{95}$. En la relación de Córdoba con sus fuentes, se vuelve a comprobar no tanto incultura ${ }^{96}$, cuanto una mezcla de erudición, exhibicionismo y precipitación: «En otras palabras, Fernando citaba textos del vastísimo almacén de su memoria sin ninguna preocupación por ser preciso (aunque podía resultar más o menos correcto), pero con toda la intención de hacer esta mezcla impresionantemente erudita» ${ }^{97}$. Otra de las características que se extraen de este retrato es la de un Fernando buscador de favores eclesiásticos y, en cierta medida, de pensador mercenario ${ }^{98}$.

Antes de centrarnos en las consideraciones histórico-filosóficas de este trabajo, se han de resaltar sus aportaciones en el campo estrictamente biográfico. Las contribuciones tanto corrigen algunas notas de la personalidad de Córdoba como sacan a la luz algunos datos desconocidos. La más importante de las correcciones desacredita a Córdoba no sólo como confesor de Alfonso de Aragón, sino incluso como sacerdote, pues Monfasani recuerda que solo hay constancia del grado de subdiaconato 99 . Apoyándose sobre la publicación de Alfredo Mauro, el estudioso recuerda que no sólo es implausible que un recién llegado -que en el mejor de los casos no pasaba de los 21 años- fuera designado como confesor del rey, sino que, para salir de dudas, otorga el nombre del confesor de Alfonso V en 1444: Fernando Valenza. También sospecha que Córdoba no fue enviado a Nápoles por Juan II en misión diplomática ${ }^{100}$.

Aunque recuerda que este campo está todavía abierto a nuevas precisiones y a la aparición de documentos ${ }^{101}$, gracias a este estudio, la biografía de Fernando de Córdoba alcanza una mayor continuidad temporal. ¿Qué secciones de la vida de Córdoba quedan enriquecidas por la aportación de Monfasani? Para responder con claridad a esta pregunta, se puede hacer un pequeño resumen de lo que se sabía

95 Ibidem, p. 45: «I doubt Fernando ever wrote it».

96 Monfasani queda impresionado por el conocimiento de Fernando de una obra de Juan de Filopón.

Ibidem, p. 42: «So the fact that Fernando knew of this commentary is a tribute to his erudition».

97 Ibidem, p. 47.

98 Esta actitud caracteriza toda la biografía de Fernando de Córdoba. De este modo, tras la muerte de Besarión, «Fernando made it his business to cultivate the favor of other cardinals» (ibidem, p. 41).

99 Ibidem, p. 8.

100 Ibidem, p. 9.

101 Ibidem, p. 24: «This blitz of documents does not mean that Fernando indulged in benefice hunting for only a few years. Rather the documents are the remains of what was probably a fairly constant pursuit which the fortuitous survival of the documents and my ability to identify them have allowed us to follow in detail for the early 1460s. We have already seen a similar succession of papal documents in 1448-1449. Further methodical searches in the Vatican's Archivio Segreto will no doubt produce others, but, at the moment, our best evidence concerning Fernando after the early 1460s are his extant writings». 
acerca de la biografía de Córdoba hasta la publicación de este trabajo. En 1444 Fernando de Córdoba llega a Nápoles, de donde parte hacia París. También era conocido que regresa del norte en la primavera de 1446, cuando disputa en Génova. Salvo por el comentario de Juan de Lucena que habla de la admiración que suscita en el rey de Hungría, Córdoba desaparece hasta su contacto con el cardenal Besarión en la década de los sesenta del siglo XV. Las aportaciones de Monfasani se producen en dos periodos. En primer lugar, y más sustantivamente, ofrece dos nuevos episodios -ambos correspondientes a la segunda mitad de la década de los cuarenta del siglo XV- posteriores a la disputa de Génova. En segundo lugar, aunque sin realizar ningún descubrimiento sustantivo, describe la situación de Córdoba como pensador papal tras la muerte de Besarión en 1472.

La primera novedad de la biografía de Monfasani consiste en indicar que Córdoba marchó a Siena, tras haber disputado en Génova. En la Toscana, nuevamente, vuelve a disputar, según su proceder habitual, sobre todo lo posible, obteniendo relativo éxito, pues se le vuelven a reconocer una capacidad «más de Dios que de hombre» y se le despide con una recomendación al rey de Nápoles ${ }^{102}$. El segundo episodio posee un impacto más espectacular, pues confirma la personalidad europea de Fernando de Córdoba. Desde 1446 o 1447, Fernando debía de haber entrado en el círculo del cardenal Juan de Carvajal, a quien acompaña en su viaje por Alemania y Hungría entre septiembre de 1447 y primavera de 1449103. El principal testimonio que queda de este viaje vuelve a ser la narración de una disputa de re omni scibili en septiembre de 1448 en la universidad de Viena. A pesar del positivo testimonio de Juan de Lucena, Monfasani recuerda que las actas de la facultad de Teología de Viena dan a Georg Tudel como vencedor de la disputa104.

Córdoba vuelve a aparecer en la década de los 60. Gracias a Monfasani sabemos que sirvió, quizá sólo por un año, como profesor de la universidad de Roma105. También ofrece nuevos datos sobre los últimos años de Córdoba, tras la desaparición de Besarión. Tras buscar nuevos patronos, Fernando logró acercarse al papa Sixto IV -quien también había sido miembro de la corte de Besarión- a lo largo de su pontificado. Hasta acercarse al papa - para quien ya se sabía que había trabajado, sobre todo a través del encargo de juzgar la ortodoxia de Pere Deguí-, dedicó libros al cardenal Francesco Todeschini-Piccolomini y al también cardenal español Auxias de Podio.

Antes de entrar en el análisis de la filosofía de Córdoba, cabe realizar una consideración más general de estas aportaciones biográficas y de cómo pueden iluminar aspectos de la filosofía de Córdoba. Monfasani reconocía que, a partir de 1448,

102 Ibidem, pp. 15-16.

103 Ibidem, p. 17.

104 Ibidem, p. 19.

105 Ibidem, p. 24: «The academic year 1460-1461 may, in fact, have been the only year he taught». 
los mejores documentos para construir la biografía de Córdoba son sus propios libros, aunque considera que, progresivamente, los archivos irán procurando nuevos restos, que darán a la biografía una base más segura ${ }^{106}$. Este camino que va del pensamiento a la biografía también ha de recorrerse en sentido inverso. Como si de un filósofo antiguo se tratara, del que no han perdurado más que testimonios en las obras de otros autores, muchas de las doctrinas y de las fuentes de Fernando de Córdoba se extraen de documentos de este tipo, que transmiten sobre qué puntos y con qué posición discurrió en sus famosas disputas públicas 107.

A pesar del carácter precioso de estas nuevas informaciones biográficas, el gran valor de esta monografía consiste en renovar completamente la imagen del pensamiento de Fernando de Córdoba, sobre todo la cuestión de las fuentes. Córdoba ya no aparece como un escolástico con limitado interés por Platón, caracterizado a su vez por un complejo lulismo. La palabra que mejor define las fuentes de Córdoba es la de eclecticismo108. De este modo, la obra de Fernando aparece caracterizada por una mezcla de escotismo, lulismo, platonismo y realismo tomista. La consideración de Córdoba como escotista es bibliográficamente innovadora. En la disputa de Viena, es donde más fácilmente se comprueba esta relación a partir de cuatro doctrinas: Cristo alcanzó el máximo nivel de gracia, el mundo no es exclusivamente producto del Padre, el Hijo está eternamente filiado y las personas de la Trinidad existen absolutamente y no relativamente 109 .

Asimismo, este escotismo se conecta con el lulismo. Monfasani insiste en el carácter pionero de esta convergencia entre lulismo y escotismo: «Con Fernando tenemos la primera prueba de la simbiosis de Escotismo y Lulismo en España»110. También se apresura, sin embargo, a revisar el lulismo de Córdoba, doctrina bibliográficamente asentada, a pesar de las manifestaciones contrarias del mismo filósofo. Monfasani indica, por el contrario, siempre dentro de la consideración de la lógica y de De re omni scibili, los puntos, en los que Córdoba se separa de Lulio. Tres son las diferencias fundamentales: el arte combinatoria de Fernando no es mecánico, no conduce a la demostración de los dogmas cristianos y establece una diferencia entre el orden lógico y el metafísico111. Fernando sólo habría sido partidario del principio primum in aliquo genere, el cual también aceptarían escolásticos como Tomás de Aquino y que sería una doctrina de referencia en la filosofía del Renacimiento a través de Marsilio Ficino ${ }^{112}$.

\footnotetext{
106 Ibidem: «at the moment, our best evidence concerning Fernando after the early 1460s are his extant writings».

107 Ibidem, p. 15. De este modo, se extrae la teoría de Córdoba sobre la inmortalidad del alma, así como su interpretación de Aristóteles en este punto.

108 Ibidem, p. 34: «his eclecticism renders such an assertion hazardous».

109 Ibidem, p. 20.

110 Ibidem, p. 35.

111 Ibidem, p. 32.

112 Ibidem, p. 28.
} 
El tomismo también representa un considerable papel en las fuentes de este autor. La conexión entre Fernando de Córdoba y las doctrinas de Santo Tomás sirve para reforzar la continuidad que, según Monfasani, caracteriza la vida y el pensamiento de Córdoba. El estudioso ofrece una visión de la filosofía de Alberto Magno y Tomás de Aquino impregnada de platonismo. De este modo, no puede sorprender que, en estas mismas lecturas formativas, Monfasani encuentre la filiación con los futuros trabajos sobre Platón: «puesto que los dos dominicos, Alberto y Tomás, habían incorporado una gran cantidad de neoplatonismo en sus escritos, esta lista temprada de autoridades favoritas de Fernando anticipa claramente los autores y los temas platónicos (o neoplatónicos) que se encuentran en los escritos conservados de la última parte de su vida»113.

Más complicada es la consideración de Córdoba como neoplatónico. El no ser representa un importante papel en la metafísica presentada en De re omni scibili, obra a la que el estudioso norteamericano le concede el mayor mérito filosófico114. Sin embargo, el significado del no ser difiere profundamente de las presentaciones de figuras fundamentales de la historia del neoplatonismo como Escoto Eriúgena, para quien el no ser es relativo y no absoluto ${ }^{115}$. Por otra parte, las referencias de Fernando al uno resultan escasas y poco coherentes ${ }^{116}$.

Por otra parte, el eclecticismo queda limitado, sin embargo, por el rechazo por parte de Fernando de Córdoba de la doctrina de Guillermo de Ockham. Ciertamente su realismo lógico lo aleja esencialmente del nominalismo: «Fernando arrojó el guante a los nominalistas al aceptar la visión realista de que los universales existen fuera de nuestras mentes» ${ }^{117}$. Reforzado este antinominalismo, tampoco aparece Ockham entre las listas de autoridades presentadas en París y Génova118.

Si pasamos de las fuentes a la descripción de su filosofía, Monfasani realiza, en cierta medida, un retrato tradicional de Córdoba. Amplía, sin embargo, la filosofía de Fernando a tres campos que apenas habían sido tratados por la anterior bibliografía: la psicología racional, la filosofía político-canónica y la relación entre filosofía y estilo literario. Respecto de la primera cuestión, y a través del temario de las cuestiones tratadas en su disputa de omni scibili en Siena, Monfasani establece que Córdoba no sólo defiende la demostrabilidad racional de la inmortalidad del alma,

113 Ibidem, p. 6.

114 Ibidem, p. 26: «But the De artificio is important in its own right. It is, in fact, Fernando's largest extant philosophical work».

115 Ibidem, p. 29.

116 Ibidem, p. 30: «Fenando [...] point to a Neoplatonic metaphysical hierarchy; but, again, we cannot be sure of the structure of this hierarchy since Fernando referred to "one" very briefly and nowhere suggested that it was the basis of his metaphysical system».

117 Ibidem, p. 21.

118 Ibidem, p. 6: «William of Ockham and the nominalists are conspicuous by their absence from these lists of authorities». 
sino que, en conexión con Duns Escoto, sostiene que en los textos de Aristóteles no se encuentra una prueba fuerte de la inmortalidad del alma, interpretación que Agostino Dati quiso refutar119.

Sin embargo, la ampliación más interesante del pensamiento de Córdoba se produce en el campo de la filosofía política y canónica. En la definidora cuestión de la querella de las investiduras, Fernando de Córdoba aparece como un decidido hierocrático. En la obra de los años 1467-1468, Adversus hereticos qui fraterculi dela opinione appellantur, Córdoba se introduce en la polémica creada por los fraticelli, que negaban que los religiosos pudieran tener propiedades. Fernando no se limita a negar su principal doctrina, sino que va más allá y defiende una postura completamente hierocrática. Al papa le corresponde el poder sobre todo los asuntos políticos temporales, de los que se le puede considerar como rey universal ${ }^{120}$. Interesante para esta cuestión es que Monfasani considera que Fernando de Córdoba ni siquiera leyó De falsa donatione Constantini121, confirmando que el desprecio o el desinterés por esta obra es una de las constantes del pensamiento político español entre los siglos XV y XVII ${ }^{122}$.

Esta postura político-eclesiástica, que según Monfasani pudo alejarlo del filofranciscano Besarión ${ }^{123}$, se mantiene del lado del derecho del poder religioso en las otras tres obras -De misterio pallii, De consultandi ratione y De iure medios exigendi fructus quos vulgo annatos dicunt et romani pontificis in temporalibus potestate- conectadas con su pensamiento político. De este modo, Fernando de Córdoba aparece como un decidido defensor de los derechos y privilegios del estamento eclesiástico. De hecho en De misterio pallii, defiende sus propios intereses como subdiácono del papa. Esta profesión estaba encargada de proporcionar a cardenales y patriarcas una lana especial para confeccionar sus trajes, para la cual pagaban una cierta tasa. El principal argumento de Fernando es que vender esta lana no es pecado de simonía, pues no se trata de una cuestión espiritual 124.

119 Ibidem, pp. 14-15

120 Ibidem, pp. 37-38.

121 Ibidem, p. 40: «I would not be surprised if Fernando never read Valla's Declamatio».

122 Parece que el mismo cardenal Bernardino Carvajal escribió una obra para responder al De falsa donatione Constantini, la cual -como recuerda S. Rossbach, Das Leben und die politisch-kirchliche Wirksamkeit des Kardinals B. de Carvajal, Berlín, 1892- estaría perdida. Aproximadamente ciento cincuenta años después Pedro de Ribadeneyra, Flos sanctorum [1599-1601], p. 13, seguiría criticando a Valla en la narración de la vida de San Silvestre: «Y puesto caso que algunos lo pongan en duda, lo que aquí queda referido es lo cierto». En lo que constituye un capítulo importantísimo para la historia de los estudios humanísticos en España, el opúsculo de Valla acaba de ser editada en castellano por primera vez, L. Valla, Sobre la falsa donación de Constantino, traducción y edición de A. Biosca y F. Sevillano, Akal, Madrid, 2012.

123 Ibidem, p. 39.

124 Ibidem, p. 42. 
En De consultandi ratione -obra que actualmente está perdida, aunque se conservó hasta mediados del siglo XIX- se habla de los deberes de los cardenales en su relación con el papa. Por último, en De iure medios exigendi fructus quos vulgos annatos dicunt et romani pontificis in temporalibus potestate, la única obra publicada en vida, si excluimos el prólogo a la edición de De animalibus de Alberto Magno, vuelve a tratar de estas cuestiones, a pesar de que la única parte conservada se dedicaría, en principio, a este peculiar impuesto de los annatos. Esta obra, que «defendía agresivamente los intereses eclesiásticos» 125 insiste en la doctrina del poder supremo del papa sobre los asuntos temporales, la cual, a pesar del título que se da al primer libro, es la principal idea de este escrito ${ }^{126}$. Monfasani no analiza pormenorizadamente, sin embargo, el contenido de este escrito, sino que se dedica a analizar los apéndices, que le sirven para determinar la erudición de este autor ${ }^{127}$.

La última gran cuestión en la que esta monografía resulta innovadora estriba en la atención que Córdoba da a la defensa de la elegancia del latín de Alberto Magno. Con este apunte, en el que Monfasani vuelve a ser original, se otorga un argumento para la disputa sobre el carácter renacentista de este pensador. Si el rechazo de los argumentos de De falsa donatione Constantini alejan a Córdoba de uno de los textos que hoy se consideran emblemáticos y fundadores del humanismo, la apología del latín de Alberto resulta más ambivalente. Por un lado, la defensa de un autor bárbaro alejaría a Córdoba de la elegancia expresiva que a la filosofía exigían muchos de los más prestigiosos humanistas. Por otro lado, el hecho de que reivindique a Alberto Magno en la misma sede lingüística que los humanistas reclaman para sí muestra que en Fernando de Córdoba ya existen criterios que no se pueden considerar medievales. Para Córdoba, Alberto Magno habrá de ser alabado, al menos en parte, por los méritos lingüísticos, consideración que supone un giro humanista en su filosofía. Se debe recordar que este juicio sobre la altura literaria de Alberto Magno no es del todo extraño al mismo humanismo. En una de las enciclopedias del Renacimiento, Giovio, quizá con un juicio algo forzado por ser Alberto Magno el retrato con que se abren los Elogia, afirma de este filosófo «postquam docendo scribendoque theologiae philosophiaeque totius locos omnes miris celsissimi ingenii tui luminibus illustrasti» 128 . Oblicuamente los Elogia acercan

\footnotetext{
125 Ibidem, p. 45.

126 Ibidem.

127 Ibidem, pp. 46-47.

128 P. Giovio, Gli elogi degli uomini illustri, edición de R. Meregazzi, Istituto Poligrafico dello Stato, Roma, 1972, p. 40. Hay que señalar, sin embargo, que en los textos -la correspondencia entre Ermolao Barbaro y Giovanni Pico della Mirandola- más importantes de este disputa Alberto Magno aparece, junto a Escoto y Santo Tomás, como representantes prototípicos de un estilo pobre. G. Pico della Mirandola en F. Bausi, Filosofia o eloquenza, Liguori, Nápoles, 1998, p. 38: «Perdiderim ego, inquam, apud Thomam, Ioannem Scotum, apud Albertum, apud Averroes meliores annos, tantas vigilias, quibus potuerim in bonis litteris fortasse nonnihil esse!».
} 
ligeramente a Fernando de Córdoba al humanismo por otro motivo. Monfasani informa, ofreciendo de nuevo un dato que nadie antes había utilizado, de que uno de los retratados por Giovio, el médico de los Médicis Piero Leoni, poseyó dos manuscritos de Córdoba ${ }^{129}$.

\section{VII}

Lamentablemente, las dos décadas que han transcurrido desde la publicación de Monfasani no han resultado prolíficas para los estudios de Fernando de Córdoba. Apenas se pueden contar cuatro trabajos, tres de ellos relacionados con la Suma de la flor de cirugía, obra cuya autoría no se le reconoce con seguridad a Córdoba.

En 2005 José Ignacio Pérez Pascual editó la Suma de la flor de cirugía. El interés por el que este estudioso se acerca a Córdoba es el de la historia de la lengua española. El análisis de este escrito serviría para enriquecer el habitual acceso a la historia de la lengua, que habitualmente ha mostrado una gran preferencia por la literatura ${ }^{130}$. A pesar de dedicarle una larga y correcta introducción a Fernando de Córdoba, Sánchez Pascual no considera haber demostrado -en cierta medida ni siquiera lo intenta- que esta obra pueda atribuírsele. De hecho, el amplio capítulo dedicado a Fernando de Córdoba en la introducción al texto lleva el título de "El posible autor de la Suma de la flor de cirugía»131. Se puede reprochar, sin embargo, al editor no hacer gala de esta incertidumbre en el título de la obra. Tampoco coteja la Suma de la flor de cirugía con otras obras de Fernando de Córdoba de carácter más científico. Sobre todo, la comparación con De secretis podría haber resultado fructífera para la determinación de la autoría. La atribución es tan insegura por parte del editor que el único argumento que da sirve más para negarla que para confirmarla: «Dista mucho, por tanto, de ser un hecho probado que ese Fernando de Córdoba que nos es bien conocido fuera el verdadero autor de este tratado. La propia Suma de la flor de cirugía no es, por otro lado, como veremos, un texto para cuya confección se necesitase precisamente de la portentosa erudición que se supone al filósofo del XV; más bien parece una recopilación escasamente elaborada de fragmentos de diversa procedencia, como tantos florilegios de la

\footnotetext{
129 Ibidem, p. 49: «The personal physician of Lorenzo de' Medici, Pier Leoni, owned the sole extant manuscript of the De secretis. He also owned one of the two extant copies of Fernando's De misterio pallii. Since Leoni lived for a while in Rome in the later fifteenth century, he very well might have been an acquaintance of Fernando»».

130 J. I. Pérez Pascual, "Algunas aportaciones de la Suma de la flor de cirugía al conocimiento del léxico medieval castellano" en J. A. Bartol Hernández et al. (Eds.), Estudios filológicos en homenaje a Eugenio de Bustos Tovar, Sígueme, Salamanca, 1992, p. 750.

131 J. I. Pérez Pascual, Suma de la flor de cirugía de Fernando de Córdoba, Toxosoutos, La Coruña, 2002, pp. 27-46.
} 
época. Con todo, no puede tampoco descartarse esa paternidad que el manuscrito, en principio, parece otorgarle» 132 .

Por último, hay que dirigir la atención al ya polémico Diccionario Biográfico Español en cuyo volumen XIV se incluye una voz sobre Fernando de Córdoba. A pesar de los límites de esta entrada, la importancia de la publicación obliga a hacer un detallado recuento de los errores. Al ser una obra de referencia podría sembrar de imprecisiones los escasos estudios sobre este pensador. En primer lugar, en un texto de aproximadamente 650 palabras, se cuentan tres erratas, lo que informa de un importante descuido editorial. No hace falta salir del título de la voz para toparse con la primera de ellas, la cual afirma que es Burgos el lugar natal de este pensador. Aunque podría tratarse de un error, la primera frase de la entrada - «natural de la ciudad de donde toma su apellido» ${ }^{133}$ - muestra que el problema se debe a problemas de revisión. En el tercer párrafo nos encontramos, Chronicon Sponheimense se le llama Chronicon Spanheimense. En el quinto se puede leer ochamista.

Pasemos a los errores de los que el autor es el responsable. El primero se encuentra también en el título. El autor parece desconocer la polémica sobre la fecha de nacimiento del autor y considera 1425 como la fecha indudable del natalicio. De esta forma, no tiene en cuenta ni el monumento fúnebre de Fernando originalmente erigido en Santiago degli Spagnoli, ni la opinión de parte de la bibliografía más autorizada que, desde Havet hasta Monfasani, se han inclinado por 1421. Por otro lado, si el autor acepta la fecha tardía, debería haber señalado las dudas presentes en los documentos con lo que el año no habría de ser 1425, sino 1425 ó 1426134. También el autor se equivoca con el año de muerte, pues introduce un circa, que parece poner en duda la información transmitida por la ya mencionada lápida. Los límites temporales de la vida del cordobés suponen una verdadera cruz, pues introducen un error en la primera referencia bibliográfica incluida en la voz, quitándole seis años de vida al autor. El título de la monografía de Bonilla y San Martín aparece transformado de la siguiente manera: Fernando de Córdoba (¿14251480? [sic]) y los orígenes del Renacimiento filosófico en España 135.

Aunque incluye a Monfasani en su bibliografía, el autor parece no haberlo leído pues continúa considerando a Córdoba confesor de Alfonso el Magnánimo, sin tener en cuenta la precisión que había llevado a cabo el estudioso estadounidense.

\footnotetext{
132 Ibidem, p. 46.

133 "Fernando de Córdoba" en Diccionario biográfico español, Real Academia de la Historia, Madrid, 2009, vol. XIV, p 534.

134 Por ejemplo, declara Valla en 1444 en J. Monfasani, Fernando of Cordova. A Biographical and Intellectual Profile, cit., p. 3 (nota): «duodevicesimum agens annum aut modo ingressus undevicesimum, nondum malas signante lanugine».

135 Tanto el circa como la fecha de 1480 nos parece que pueden haber sido influencia de la información que Wikipedia transmite equivocadamente en su entrada sobre nuestro autor: http://es.wikipedia.org/wiki/Fernando_de_Córdoba_(filósofo) (consulta del 19 de septiembre de 2011).
} 
Si nos trasladamos al plano de las fuentes de Córdoba, el autor afirma: «Ataca con dureza las tesis de Raimundo Lulio y desprecia las aportaciones personales del pensador mallorquín, valorando tan sólo los argumentos tomados del Estagirita»136. Este juicio resulta sorprendente, pues no sólo desconoce una de las principales corrientes de la bibliografía, sino que atribuye esta negativa actitud de Fernando de Córdoba respecto del lulismo a las obras que escribió sobre Platón y no a De re omni scibili, que, hasta la fecha, es la obra de donde se extrae el material para juzgar el lulismo o el antilulismo de este pensador.

Aunque en un marco más general, igualmente imprecisas son las siguientes afirmaciones: «Cuando la práctica totalidad de las escuelas de Europa medieval, entendían, por puro desconocimiento de ambos maestros, que Platón era la síntesis de Aristóteles, su profundidad intelectual le permitió percibir que no constituían polos diametralmente opuestos» ${ }^{137}$. Por último, el autor se prodiga en juicios sobre una obra que se ha perdido como es De duabus philosophiis, et praestantia philosophiae Platonis supra Aristotelem. Bien es cierto que, si nos atenemos al cuerpo de la entrada, nada sabemos del extravío de esta obra, cuya última noticia segura proviene del inventario de la biblioteca de Besarión realizado en 1474. La entrada se cierra con unas consideraciones muy arriesgadas, sobre las que no queremos seguir abundando al no afectar directamente a la figura de este pensador ${ }^{138}$.

\section{VIII}

En 1882, Fernando de Córdoba irrumpía entre los estudiosos de la historia del pensamiento como una figura romántica, que con sus conocimientos, juventud y habilidades impresionaba a la más importante universidad del orbe. 30 años más tarde, Córdoba se trasladaba a España como protagonista de un capítulo de la historia de la lógica, pero, sobre todo, como una figura por la que los partidarios de la importancia de la historia de la filosofía española, deseosos de encontrar a algún legitimador héroe, no se pueden entusiasmar. Se establece, por tanto, de manera definitiva -incluso entre aquellos que propugnan la importancia de la filosofía hispánica- la imagen de Fernando de Córdoba como fracasado, como promesa incumplida de un Renacimiento que hasta el siglo XVI no se iba a asentar plenamente en la Península. Esta limitada figura -fracasado incluso para historiografía española obsesionada con encontrar un redentor- se extingue sólo en 1992 gracias a

\footnotetext{
136 Ibidem, p. 535.

137 Ibidem, p. 535.

138 Ibidem: «Algunos estudiosos lo juzgan, en cuanto a su aspiración por refundir Academia y Liceo y a alcanzar una Unidad por encima de las antinomias como precursor de Leibniz y Krause». No hemos podido localizar el origen de esta comparación.
} 
Monfasani. Córdoba aparece como un intelectual que se expresa con cierta soltura, con profesional decencia por numerosos campos del saber: lógica, metafísica, estudios platónicos, medicina, eclesiología, incluso dedica a sus propios intereses toda una obra. Tan alejado del salvador de una avergonzada cultura como del joven sabio y despreocupado, Fernando de Córdoba pierde en este último escalón de la bibliografía todo romanticismo, incluso la pequeña porción que subsistía en el desilusionado cuadro de Bonilla. Vitalmente, Córdoba aparece como un cómodo superviviente, que busca el apoyo de los grandes de la Iglesia, a través de consideraciones históricas y de posturas teóricas y políticas, que, si bien sería injusto considerarlas interesadas, seguro que no habían de producirle ningún problema.

¿Cómo se relaciona este nuevo Fernando de Córdoba con la filosofía española del siglo XV? Desde un punto de vista general, se puede afirmar que los estudiosos, al haberse librado del mito del Renacimiento, evitan las condenas que, por una cierta preconcepción, algunas veces se han dirigido contra este autor. Una buena cuota de la responsabilidad de la mirada negativa de Bonilla, aunque lo mismo valdría para Menéndez y Pelayo, se debe a que en Córdoba no se encarnaban plenamente los ideales renacentistas preconizados por Burckhardt. La delimitación del concepto de Renacimiento no ha dejado de interesar a los estudiosos, sin embargo, no sirve -al menos no cumple ninguna función en el trabajo de Monfasani- para condenar, criticar o, simplemente, juzgar a este autor.

Más particularmente, aunque también desde la mirada del concepto de Renacimiento, la figura de Córdoba recuerda y realza la importancia que los escritores españoles tuvieron en los primeros pasos de la imprenta en Roma. Si Monfasani señala acertadamente la relación que Adversus hereticos qui fraterculi dela opinione appellantur hubo de tener con la disputa eclesiástico-política protagonizada por Juan de Torquemada y Rodrigo Sánchez de Arévalo, no recuerda, sin embargo, la importancia que, para la historia de la imprenta en Roma, ostentan ambos pensadores ${ }^{139}$. De este modo, los dos textos publicados -la edición de $D e$ animalibus de Alberto Magno y el propio De iure medios exigendi fructus quos vulgos annatos dicunt- por Fernando de Córdoba en Roma se suman a esta importante presencia, que otorga una renovada importancia al pensamiento castellano en uno de los centros del Renacimiento.

¿Qué visión general se extraen de estas aportaciones biográficas en el contexto del pensamiento español del siglo XV? Desde el punto de vista biográfico, la figura de Córdoba se confirma como un personaje netamente europeo. Como tantos otros pensadores relacionados con la curia es una figura principalmente italiana, pero sus hipotéticas misiones diplomáticas, su servicio a cardenales y, sobre todo,

139 R. Sánchez de Arévalo, lo que lo confirma como paralelo de Fernando de Córdoba, también escribió una obra que examinaba la doctrina de los fraticelli. R. Sánchez de Arévalo, Libellus de paupertate Christi et apostolorum, 1466 (edición moderna por P. Toni en Razón y fe, CV, 1934). 
sus disputas internacionales y numerosos viajes -por muchos que no sean tantos como el propio Córdoba confiesa- lo convierten en un modelo y en un antecedente de la filosofía española que se vuelca en Europa o que sólo en ella encuentra un lugar para expresarse.

Si nos dirigimos ahora a las fuentes y al pensamiento personal de Córdoba, el rechazo del nominalismo lo mantiene unido a los pensadores españoles peninsulares, donde esta corriente no se instaura hasta comienzos del siglo XVI con la fundación de la cátedra nominalista de la Universidad de Alcalá de Henares. De este modo, Córdoba se aleja esta vez de los españoles que en el extranjero profesaban y estudiaban en cátedras nominalistas. Por su parte, el eclecticismo de tomismo, escotismo y lulismo lo mantiene al margen de la polémica que entre escotistas y tomistas se produce en España y en toda Europa a lo largo de los siglos XIV y XV140. Es en el campo de la historia de las ideas políticas y de la historia del platonismo del siglo XV español donde esta renovada imagen bibliográfica de Fernando de Córdoba representa su más importante papel. En el de las ideas políticas, Córdoba habrá de figurar como un pensador secundario, pero que, sin embargo, aporta profundidad al debate filosófico político que, en España, habían centrado Torquemada, el Tostado o Sánchez de Arévalo. En la historia del platonismo hispánico, la edición de De laudibus Platonis le habrá de situar en un lugar principal, cercano al de Pedro Martínez de Toledo o Juan de Lucena.

\author{
Miguel Saralegui \\ Universidad Diego Portales (Chile) \\ miguelsaralegui@gmail.com
}

\footnotetext{
140 Para este periodo sigue resultando fundamental la obra en muchos puntos anticuada: T. Carreras y Artau y J. Carreras y Artau, Historia de la filosofía española. Filosofía cristiana de los siglos XIII al $X V$, cit., vol. II, pp. 531-649.
} 